NBER WORKING PAPER SERIES

\title{
BUBBLES, FINANCIAL CRISES, AND SYSTEMIC RISK
}

\author{
Markus K. Brunnermeier \\ Martin Oehmke \\ Working Paper 18398 \\ http://www.nber.org/papers/w18398 \\ NATIONAL BUREAU OF ECONOMIC RESEARCH \\ 1050 Massachusetts Avenue \\ Cambridge, MA 02138 \\ September 2012
}

This chapter was written for the Handbook of the Economics of Finance, Volume 2. We are grateful to Patrick Cheridito, Thomas Eisenbach, Stephen Morris, Delwin Olivan, René Stulz, Dimitri Vayanos, and Eugene White for helpful comments on earlier drafts of this chapter. The views expressed herein are those of the authors and do not necessarily reflect the views of the National Bureau of Economic Research.

At least one co-author has disclosed a financial relationship of potential relevance for this research. Further information is available online at http://www.nber.org/papers/w18398.ack

NBER working papers are circulated for discussion and comment purposes. They have not been peerreviewed or been subject to the review by the NBER Board of Directors that accompanies official NBER publications.

(C) 2012 by Markus K. Brunnermeier and Martin Oehmke. All rights reserved. Short sections of text, not to exceed two paragraphs, may be quoted without explicit permission provided that full credit, including (C) notice, is given to the source. 
Bubbles, Financial Crises, and Systemic Risk

Markus K. Brunnermeier and Martin Oehmke

NBER Working Paper No. 18398

September 2012

JEL No. G00,G01,G20

\title{
ABSTRACT
}

This chapter surveys the literature on bubbles, financial crises, and systemic risk. The first part of the chapter provides a brief historical account of bubbles and financial crisis. The second part of the chapter gives a structured overview of the literature on financial bubbles. The third part of the chapter discusses the literatures on financial crises and systemic risk, with particular emphasis on amplification and propagation mechanisms during financial crises, and the measurement of systemic risk. Finally, we point toward some questions for future research.

\author{
Markus K. Brunnermeier \\ Princeton University \\ Department of Economics \\ Bendheim Center for Finance \\ Julis-Rabinowitz Center for Finance and Public Policy \\ Princeton, NJ 08540 \\ and NBER \\ markus@princeton.edu \\ Martin Oehmke \\ Finance and Economics Division \\ Columbia Business School \\ 3022 Broadway, Uris Hall 420 \\ New York, NY 10027 \\ moehmke@columbia.edu
}




\section{Contents}

\begin{tabular}{lll}
\hline 1 & Introduction & 3
\end{tabular}

\begin{tabular}{|llll}
2 & A Brief Historical Overview of Bubbles and Crises & 7
\end{tabular}

$\begin{array}{lll}3 & \text { Bubbles } & 12\end{array}$

3.1 Rational Bubbles without Frictions . . . . . . . . . . . . . . . . . . . . 14

$3.2 \quad$ OLG Frictions and Market Incompleteness . . . . . . . . . . . . . . . . 17

3.3 Informational Frictions . . . . . . . . . . . . . . . . . . . . . . . . . . . 19

3.4 Delegated Investment and Credit Bubbles . . . . . . . . . . . . . . . . 22

3.5 Heterogeneous-Beliefs Bubbles . . . . . . . . . . . . . . . . . . . . . . . 24

$3.6 \quad$ Empirical Evidence on Bubbles . . . . . . . . . . . . . . . . . . . . 27

3.7 Experimental Evidence on Bubbles . . . . . . . . . . . . . . . . . . . . 28

\begin{tabular}{lll}
\hline & Crises & 30
\end{tabular}

4.1 Counterparty/Bank Runs . . . . . . . . . . . . . . . . . . . . 32

4.1 .1 Bank Runs as a Sunspot Phenomenon . . . . . . . . . . . . . . 34

4.1 .2 Information-induced Bank Runs . . . . . . . . . . . . . . . . . . 35

4.2 Collateral/Margin Runs . . . . . . . . . . . . . . . . . . . . 40

4.2 .1 Loss Spiral. . . . . . . . . . . . . . . . . . . . . . 41

4.2 .2 Margin/Haircut or Leverage Spiral . . . . . . . . . . . . . . . . 44

4.2 .3 Contagion and Flight to Safety . . . . . . . . . . . . . . . . . . 48

4.3 Lenders' or Borrowers' Friction? . . . . . . . . . . . . . . . . . . . . . . 49

4.4 Network Externalities . . . . . . . . . . . . . . . . . . 52

4.5 Feedback Effects between Financial Sector Risk and Sovereign Risk . . 57

5 Measuring Systemic Risk $\quad 60$

$5.1 \quad$ Systemic Risk Measures . . . . . . . . . . . . . . . . . . . . . 60

5.2 Data Collection and Macro Modeling . . . . . . . . . . . . . . . . . . 63

5.3 Challenges in Estimating Systemic Risk Measures . . . . . . . . . . . . 65

5.4 Some Specific Measures of Systemic Risk . . . . . . . . . . . . . . . . . 67

$\begin{array}{lll}6 & \text { Conclusion } & 71\end{array}$ 


\section{Introduction}

Bubbles, crashes, and financial crises have been recurring phenomena in financial markets from their early days up to the modern age. This chapter surveys and links the literature on bubbles, financial crises, and systemic risk. The overarching structure of this chapter arises from distinguishing two phases that play a role in almost all financial crises: (i) a run-up phase, in which bubbles and imbalances form, and (ii) a crisis phase, during which risk that has built up in the background materializes and the crisis erupts. To illuminate the run-up phase, our survey draws on the large literature on bubbles and asset price booms. To understand the crisis phase, we draw on models of amplification mechanisms that occur after a bubble bursts. Finally, we stress that the run-up and crisis phase cannot be seen in isolation - they are two sides of the same coin. This has important implications for the emerging literature on measuring systemic risk.

Section 2 provides a brief historical account of bubbles and financial crises. While the discussion is kept brief, we point the reader to further sources on the historical episodes we discuss.

During the run-up phase, discussed in Section 3, asset price bubbles and imbalances form. Most of the time, these imbalances build up slowly in the background and volatility is low. Initially, the imbalances that ultimately lead to a financial crisis are often hard to detect. For example, at first a boom in asset prices can often be rationalized by appealing to some form of innovation. This innovation could be technological change (e.g., railroads, telegraphs, the internet), financial liberalization (e.g., the removal of Regulation Q), or financial innovation (e.g., securitization). However, as the bubble gains momentum, it ultimately becomes clear that the fundamental improvements that may have warranted an initial increase in asset prices cannot keep up with ever-increasing valuations. A bubble has formed.

The run-up phase often causes incentive distortions for agents in the economy. These incentive distortions can either be the consequence of rational behavior, or may be caused by behavioral belief distortions. Rational distortions occur when agents in the economy rationally respond to the incentives they face during the run-up phase. These include, for example, moral hazard problems that arise from expected bailouts or policies like the "Greenspan put." They also include over-leveraging or over-investment that result from potential fire-sale externalities. Such externalities can arise when individual households or firms take potential drops in asset prices as given when making their investment decision, not internalizing that it is their joint investment decision that 
determines the size of the crash.

Belief distortions occur because often there are insufficient data to establish that a bubble is forming. For example, if there has never been a nationwide decline in nominal house prices, agents may extrapolate that house prices will also not decline in the future (extrapolative expectations). Market participants are especially prone to such extrapolative expectations if there is a lack of data. Alternatively, belief distortions may be based on the "this-time-is-different" rationale. While the asset price boom observed may be out of line with historical data, agents may choose to ignore this by arguing that something fundamental is different this time around, such that cautionary signals from history do not apply.

The ideal breeding ground for the run-up phase is an environment of low volatility. Usually, during such times, financing is easy to come by. Speculators can lever up, lowering the return differential between risky and less risky securities. The resulting leverage and maturity mismatch may be excessive because each individual speculator does not internalize the externalities he causes on the financial system. For example, when levering up with short-term debt, each speculator only takes into account that he might not be able to roll over his debt and might be forced to sell off assets at fire-sale prices. However, the same investor does not take into account that his selling will depress prices, potentially forcing others to sell as well, exacerbating the fire sale. Put differently, financial stability is a public good. Because everyone profits from it, individual traders may have insufficient incentives to contribute to it.

In Section 4 we turn to the crisis phase, which starts when, after the gradual buildup of a bubble and the associated imbalances, a trigger event leads to the bursting of the bubble. This sudden transition has sometimes been referred to as a "Minsky moment." The Minsky moment can occur long after most market participants are aware, or at least suspicious, that a bubble has built up in the background. Overall, the main problem is not the price correction per se, but the fact that the necessary correction often occurs only very late, at which point risk and large imbalances have built up. The trigger event that catalyzes the crisis does not have to be an event of major economic significance when seen by itself. For example, the subprime mortgage market that triggered the recent financial crisis made up only about $4 \%$ of the overall mortgage market. However, because of amplification effects, even small trigger events can lead to major financial crises and recessions.

During the crisis phase, amplification mechanisms play a major role. These amplification mechanisms both increase the magnitude of the correction in the part of the 
economy that was affected by a bubble and spread the effects to other parts of the economy. Amplification mechanisms that arise during financial crises can either be direct (caused by direct contractual links) or indirect (caused by spillovers or externalities that are due to common exposures or the endogenous response of various market participants). A good example of direct spillover effects are bank runs of different forms, such as classic depositor runs or their modern reincarnation as counterparty runs. As a crisis erupts, bank depositors and other short-term creditors to financial institutions may decide to take out their funding, thus amplifying the crisis. Another example of direct spillovers are so-called domino effects. For example, the failure of one bank may affect another bank that is a creditor to the failed institution. Thus, domino effects are closely related to interconnectedness within a network of institutions. Then there are indirect spillovers that, rather than through direct contractual relations, work indirectly through the price mechanism. For example, the fire-sale liquidation of assets by one bank may drive down the marked-to-market value of another bank's portfolio, potentially causing this second bank to also sell assets. These indirect spillover effects are closely related to fire-sale externalities and liquidity spirals.

When it comes to amplification, an important distinction is whether the imbalances that formed during the run-up (or bubble) phase were fueled by credit. The reason is that the bursting of credit bubbles leads to more de-leveraging and stronger amplification mechanisms. For example, while the bursting of the technology bubble in 2000 caused significant wealth destruction, its impacts on the real economy were relatively small when compared to the bursting of the recent housing bubble. The distinguishing feature of the housing bubble was the preceding credit boom. Similarly, the run-up in stock prices during the Roaring Twenties was to a large extent based on credit in the form of margin trading, i.e., it was financed via short-term loans. This credit-fed boom ultimately led to the Great Depression. Similarly, the Scandinavian crisis in the early 1990s and the Japanese "lost decade" were also preceded by lending booms that had led to excessive asset prices.

While financial crises often erupt suddenly, recovery from crises often takes a long time. This happens because the negative shock caused by the bursting of the bubble leads to persistent adverse effects and deep and drawn-out recessions. For example, output typically recovers only slowly after a financial crisis. Even after policy responses, such as a recapitalization of the banking system, recovery is typically sluggish. This is the case because balance sheets of other agents might still be impaired. For example, the recent crisis in the U.S. severely impaired household balance sheets. Rebuilding these 
balance sheets takes time and thus prolongs the crisis. The bursting of the Japanese real estate and stock market bubbles in the 1990s, on the other hand, impaired corporate and bank balance sheets, which was one of the contributing factors to the lost decade(s) in Japan.

In Section 5, we close our discussion of financial crises by discussing measures of systemic risk. Because of the large social costs of financial crises, such measures, if available in a timely manner, could serve as early-warning signals for policy makers. The development of such measures, a research agenda that is still in its infancy, requires two steps. First, it is necessary to develop a conceptual framework for measuring systemic risk in a coherent fashion. The second step involves putting in place data collection systems that allow the timely computation of such systemic risk measures. We conclude this section by discussing a number of specific systemic risk measures that have been proposed in the literature.

Finally, in Section 6 we highlight a number of open questions to be addressed in future research. This, of course, is not meant as an exhaustive list of future research questions in this field. Rather, it should be read as a somewhat personal list of topics that we believe could use further study.

In writing this chapter, we had to draw the line in terms of what to include. One important area that we do not cover is the sovereign and international dimension of financial crises. Even financial crises that are local in origin often develop an international dimension. For example, financial crises may be associated with large exchange rate movements that occur when countries devalue their currency or come under speculative attack. Such currency crises may go hand in hand with banking crises and those two channels may reinforce each other, a phenomenon that has become known as twin crises (Kaminsky and Reinhart (1999)). Currency devaluation deepens banking crises (and real private-sector indebtedness) if debt is denominated in foreign currency, something often referred to as the "original sin" of emerging economies. Banking crises may lead to sovereign debt crises (Reinhart and Rogoff (2011)) and countries may default on their external (and potentially also domestic) debt. While these sovereign and international dimensions are important aspects of financial crises, they go beyond the scope of this chapter. Instead, we refer the reader to Reinhart and Rogoff (2009) and, for an in-depth discussion of recent sovereign crises, Sturzenegger and Zettelmeyer (2006). 


\section{A Brief Historical Overview of Bubbles and Crises}

Historically, bubbles, crashes, and financial crises have occurred with striking regularity. There is evidence for bubbles and crises during all time periods for which we have financial data. Moreover, bubbles and crises have occurred in financial markets at all stages of development: developed financial systems as well as emerging economies and developing financial markets. This section provides a brief summary of the most important crisis episodes. Additional detail on these episodes can be found, for example, in Kindleberger (1978), Shiller (2000), Allen and Gale (2007), and Reinhart and Rogoff (2009).

While each particular boom and each particular crisis is different in its details and specificities, there are recurring themes and common patterns. For example, in the typical anatomy of a financial crisis, a period of booming asset prices (potentially an asset price bubble), initially triggered by fundamental or financial innovation, is followed by a crash. This crash usually sets off a number of amplification mechanisms and, ultimately, this often leads to significant reductions in economic activity. The resulting declines in economic activity are often sharp and persistent.

The earliest examples of debt crises and debt forgiveness are from Mesopotamia. Merchants extended credit to farmers, but when harvests turned out worse than expected, farmers regularly ended up overindebted, leading to social unrest and threatening the social order (see, for example, Graeber (2011)). This led to the practice of "cleaning the slate": From time to time debts were wiped out and farmers given a fresh start. In similar fashion, in ancient Greece, the Solonic reforms of $594 \mathrm{BC}$ canceled debts and outlawed enslavement for debt in order to improve the situation of debt-ridden farmers.

Maybe the best-documented early examples of asset price bubbles are the Dutch tulip mania (1634-37), the Mississippi Bubble (1719-20), and the South Sea Bubble (1720). Each of these episodes involved spectacular rises in the prices of certain assets (the price of tulips, shares in the Mississippi Company, and shares in the South Sea Company, respectively), followed by precipitous declines in the prices of these assets (for more detailed accounts of these episodes, see Neal (1990, 2012) and Garber (2000)). These crises also serve as an early example of potential contagion. As Kindleberger (1978) points out, many British investors had bought shares in John Law's Mississippi Company in Paris, while many investors from the Continent had purchased South Sea Company shares in London. Schnabel and Shin (2004) also document contagion 
during the northern European financial crisis of 1763, which involved highly levered and interlocked financial ties between Amsterdam, Hamburg, and Prussia and resulted in significant asset fire sales by affected market participants. The crisis of 1763 also highlights the role of financial innovation, in this case in the form of bills of exchange that facilitated leverage.

During the 19th century, the U.S. suffered a multitude of banking crises. Before the creation of a national banking system in 1863-65, major banking crises occurred in the U.S. in 1837 and in 1857. After the creation of a national U.S. banking system, banking panics occurred again (in varied forms) in 1873, 1884, 1893, 1907, and 1914. While it is hard to find good data, anecdotally many of these crises were preceded by land bubbles (before the Civil War) or bubbles in railroad bonds (after the Civil War). Most of these panics went hand in hand with large drops in the stock market as banks cut down margin lending (see Allen and Gale (2007)) and were associated with drops in real activity as proxied, for example, by the production of pig iron (Gorton (1988)) or the Miron and Romer (1990) measure of industrial production. The panic of 1907 ultimately led to the creation of the Federal Reserve System in 1914.

During the 1920s, the U.S. saw a large stock market boom, particularly from 1927 to 1929. The Roaring Twenties were followed by the great stock market crash of 1929 and the Great Depression, including the banking panic of 1933. The Great Depression followed a typical boom-bust cycle that included a large run-up in real estate prices that peaked in 1926, followed by a crash in stock market and real estate valuations, a banking panic, and a prolonged recession. While the real estate price boom of the 1920s often receives less emphasis in analyses of the Great Depression, White (2009) argues that the real estate bubble of the 1920s was, in fact, similar in magnitude to the boom and bust cycle in real estate prices associated with the financial crisis of 2007-09.

Alongside the real estate bubble of the 1920s, the Great Depression was fueled by a bubble in the stock market. During the run-up in the stock market, many stocks were bought on margin, which meant that the stock market bubble was credit-financed. In 1928 the U.S. Federal Reserve first used moral persuasion to discourage banks from lending to speculators. It then started tightening monetary policy in February 1928 (see Friedman and Schwartz (1963)). The Federal Reserve eventually raised the interest rate in July 1929. Arguably, the actions by the Federal Reserve contributed to the stock market crash that materialized in 1929, ultimately resulting in the Great Depression. The Great Depression ultimately caused a full-blown international banking crisis, starting with the failure of the largest bank in Austria, Credit-Anstalt, in 1931. 
Since the Great Depression, banking panics have become rare in the U.S., mostly because of the creation of the Federal Reserve System in 1914 and introduction of deposit insurance as part of the Glass-Steagall Act of 1933. But this did not eliminate financial crises. For example, the savings and loan crisis of 1979 led to the failure of no fewer than 747 savings and loan institutions. As the Federal Reserve started raising interest rates to rein in inflation, short-term funding costs of savings and loan institutions exceeded the returns of the assets they were holding. For most savings and loan institutions, the only way to respond was to increase the riskiness of their assets, in the hope that higher returns would offset higher funding costs. Eventually, however, most savings and loans were deeply underwater and their assets had to be taken over by the Resolution Trust Corporation that was formed in 1989. Some cite the savings and loan crisis as one of the reasons for the U.S. recession of 1990-91.

The 1970s and 1980s also witnessed large boom-bust cycles in international credit. Many South American countries borrowed considerably in international markets throughout the 1960s and 1970s to finance domestic investments in infrastructure and industry. During that period, the indebtedness of these countries soared: Kindleberger (1978) points out that the foreign debts of Mexico, Argentina, Brazil, and other developing countries increased from $\$ 125$ billion in 1972 to over $\$ 800$ billion in 1982 . However, the sharp increase in U.S. interest rates led to a devaluation of South American currencies and drastically increased the real debt burden from dollar-denominated debt in those countries. At the same time, a recession in the U.S. dried up the flow of credit to those countries. In 1982, Mexico declared it would no longer be able to service its debt. Ultimately, the South American debt crises led to the Brady Plan in 1989 (see, for example, Sturzenegger and Zettelmeyer (2006)).

Another major lending boom followed by a painful bust occurred in Scandinavia in the early 1990s. As a result, Finland, Norway, and Sweden suffered a major banking crisis during this period (see, for example, Englund (1999) and Jonung, Kiander, and Vartia (2009)). In all three countries, the crisis followed a boom in lending and asset prices, particularly for real estate, that had developed in the late 1980s following credit market liberalization earlier in the decade. The burst of the bubble led to large drops in output in all three countries. All three countries had to abandon pegs of their currencies, leading to devaluation and increases in the real indebtedness of the banking sectors in all three countries, which had borrowed in foreign currency. As a response to the crisis, the Swedish government took over part of the banking system. Finland's government extended large amounts of loans and guarantees to prop up the country's 
banking system.

Japan also suffered a major financial crisis in the early 1990s. The Japanese crisis was preceded by a boom in both real estate and the Japanese stock market. The losses from this crisis weighed on Japanese banks and the Japanese economy for years, leading to the "lost decade" of the 1990s and continuing slow growth in Japan during the 2000s.

The Japanese example illustrates the problems bubbles pose for central banks. Worried about the bubble in real estate and stock prices, the Bank of Japan started raising the official discount rate in May 1989, eventually increasing it from $2.5 \%$ to $6.0 \%$. In addition, the Bank of Japan limited the growth rate of lending to the real estate industry such that it could not exceed the growth rate of total lending ("total volume control") and forced all banks to report lending to the construction industry and nonbank financial industry. Both of these interventions forced the real estate sector to de-lever, driving down prices. Many real estate firms went bankrupt, leading to firesales in real estate. Since real estate was the primary collateral for many industries, overall lending declined, pushing down collateral value even further. Ultimately, the decrease in real estate prices led to a debt overhang problem for the entire Japanese banking sector, crippling the Japanese economy for decades (see, for example, Hoshi and Kashyap (2004)).

The mid-1990s and early 2000s also featured a return of currency and sovereign debt crises. Mexico, a success story of the early 1990s, was unable to roll over its foreign-currency-denominated debt after large fiscal deficits and a sharp decline in the value of the peso, triggering a bailout by the United States and the IMF. In 1997 and 1998, the focus fell on East Asian countries and Russia. After large equity and real estate booms in East Asia, a run on Thailand's currency (the baht) led to a reversal of international capital flows to the entire region, triggering a financial crisis that quickly spread to other East Asian countries, such as Indonesia and Korea (Radelet, Sachs, Cooper, and Bosworth (1998)). In August 1998, Russia declared a moratorium on its ruble-denominated debt and devalued its currency. Among other things, a decrease in the oil price had led to a worsening of Russia's fiscal situation, leading to rising debtto-GDP ratios, fiscal deficits, and rising interest rates. Ultimately, Russia opted not to defend its exchange rate peg and devalued its currency, declaring at the same time a moratorium on its ruble-denominated debt. The Russian banking system was rendered effectively insolvent, both from direct losses on government debt and losses from the devaluation of the ruble. Outside of Russia, the crisis led to upheaval in global financial markets and the demise of the hedge fund Long Term Capital Management (LTCM). 
This prompted the Federal Reserve Bank of New York to orchestrate a private-sector bailout for LTCM. At the same time, the Federal Reserve cut the interest rate.

In 2001 it became clear that Argentina was unable to sustain the level of publicsector debt it had accumulated over the 1990s, while the Argentinean peso was pegged to the U.S. dollar via a currency board. Despite IMF support, Argentina suffered a run on the banking system in November 2001 and had to suspend convertibility of deposits. In January 2002, Argentina suspended the peso's peg to the dollar. Within a few days, the peso lost much of its value. The crisis led to a severe decrease in GDP and a spike in inflation. Ultimately, Argentina defaulted on its debts. The Argentinian default led to at least four large debt restructurings. Argentina also highlighted the growing difficulty in resolving defaults when creditors are dispersed; more than three years passed between default and an ultimate restructuring deal. Between 2001 and 2002, output collapsed by $16.3 \%$ (for detailed summaries of the Russian crisis, Argentinian crisis, and other recent sovereign debt crises, see Sturzenegger and Zettelmeyer (2006)).

Recently, the bursting of the U.S. housing bubble and the associated financial market turmoil of 2007 and 2008 led to the most severe financial crisis since the Great Depression (for a summary, see Brunnermeier (2009)). A combination of low interest rates, financial innovation in the form of mortgage securitization, and a global savings glut had led to a boom in U.S. real estate prices that started reversing in 2007. The collapse of the real estate bubble led to the default, or near default, of a number of U.S. financial institutions, most notably Bear Stearns, Lehman Brothers, and AIG. The U.S. government responded with a massive bailout operation in the fall of 2008 . Nonetheless, the collapse of the real estate bubble led to one of the longest and deepest recessions in U.S. history.

Most recently, the European Union has been dealing with a major sovereign debt crisis. Following a lending boom during the early 2000s, a loss of competitiveness, fiscal deficits, and repercussions from the great financial crisis of 2008 led to debt crises in Greece, Ireland, Italy, Portugal, and Spain. These crises also highlight the intimate connection between banking crises and sovereign debt crises. In Ireland and Spain, a crisis in the banking sector - following a bubble in real estate and house prices - led to a sovereign debt crisis. In Italy, on the other hand, a sovereign debt crisis threatens the banking system. 


\section{Bubbles}

The term bubbles refers to large, sustained mispricings of financial or real assets. While exact definitions of what exactly constitutes a bubble vary, it is clear that not every temporary mispricing can be called a bubble. Rather, bubbles are often associated with mispricings that have certain features. For example, asset valuation in bubble periods is often explosive. Or, the term bubble may refer to periods in which the price of an asset exceeds fundamentals because investors believe that they can sell the asset at an even higher price to some other investor in the future. In fact, John Maynard Keynes, in his General Theory, distinguishes investors, who buy an asset for its dividend stream (fundamental value), from speculators, who buy an asset for its resale value.

Ultimately, bubbles are of interest to economists because prices affect the real allocation in the economy. For example, the presence of bubbles may distort agents' investment incentives, leading to overinvestment in the asset that is overpriced. Real estate bubbles may thus lead to inefficient construction of new homes. Moreover, bubbles can have real effects because the bursting of a bubble may leave the balance sheets of firms, financial institutions, and households in the economy impaired, slowing down real activity. Because of these repercussions on the real economy, it is important for economists to understand the circumstances under which bubbles can arise and why prices can deviate systematically from their fundamental value.

Hyman Minsky provided an early, informal characterization of bubbles and the associated busts. In his characterization, Minsky distinguishes between five phases (see, for example, the description of Minsky's model in Kindleberger (1978)). An initial displacement - for example, a new technology or financial innovation-leads to expectations of increased profits and economic growth. This leads to a boom phase that is usually characterized by low volatility, credit expansion, and increases in investment.1 Asset prices rise, first at a slower pace but then with growing momentum. During the boom phase, the increases in prices may be such that prices start exceeding the actual fundamental improvements from the innovation. This is followed by a phase of euphoria during which investors trade the overvalued asset in a frenzy. Prices increase in an explosive fashion. At this point investors may be aware, or at least suspicious, that there may be a bubble, but they are confident that they can sell the asset to a greater fool in the future. Usually, this phase will be associated with high trading volume. The

\footnotetext{
${ }^{1}$ For empirical studies that document increases in credit during the run-up to financial crises, see Reinhart and Rogoff (2011) and Schularick and Taylor (2012).
} 
resulting trading frenzy may also lead to price volatility as observed, for example, during the internet bubble of the late 1990s. At some point, sophisticated investors start reducing their positions and take their profits. During this phase of profit taking there may, for a while, be enough demand from less sophisticated investors who may be new to that particular market. However, at some point prices start to fall rapidly, leading to a panic phase, when investors dump the asset. Prices spiral down, often accelerated by margin calls and weakening balance sheets. If the run-up was financed with credit, amplification and spillover effects kick in, which can lead to severe overshooting also in the downturn.

Much of the theoretical literature on financial bubbles can be seen as an attempt to formalize this narrative. As we will see, often these models are good at explaining parts but not all of the Minsky framework. For example, some models generate the explosive price paths described by Minsky, but have less to say about trading volume. Other bubble models generate the associated trading volume, but may not feature explosive price paths. While the literature on bubbles has made giant strides in the last decades, it is thus probably fair to say that a comprehensive model of Minsky's narrative is still somewhat elusive.

In this section, we first survey the theoretical literature on bubbles.2 We start by describing models of rational bubbles. In this class of models, the price path of an asset that is affected by a bubble is explosive, and bubbles can usually be sustained only if their presence allows for an improvement over the allocation in the economy absent the bubble. This means that even in these rational models, some sorts of frictions (for example, stemming from an overlapping generations structure or market incompleteness) are important. Subsequently, we show that bubbles also arise naturally in models that incorporate other types of frictions. We first discuss how informational frictions allow bubbles to persist and how, in the presence of informational frictions, non-fundamental news can lead to large price corrections or crashes. We then discuss how frictions that arise from delegated investment can help sustain bubbles. In some of these models, the bubble is fueled by credit, which is an important feature since it can lead to painful amplification when the bubble bursts, a feature that we discuss in more detail in the section on crashes. Finally, we discuss models of bubbles that are based on heterogeneous beliefs across agents. In contrast to many other models of bubbles, heterogeneous-beliefs models generate the prediction that bubbles are associated with

\footnotetext{
${ }^{2}$ Parts of this section draw on Brunnermeier (2008).
} 
high trading volume, something that is often observed in practice. After surveying the theoretical literature on bubbles, we briefly discuss empirical and experimental evidence on bubbles. Here we mainly focus on the empirical literature that attempts to test for rational bubbles, and on some classic experimental results.

\subsection{Rational Bubbles without Frictions}

In models of rational bubbles, investors are willing to hold a bubble asset because the price of the asset is expected to rise in the future. A bubble can be sustained today because the bubble is expected to grow in the future, at least as long as the bubble does not burst. While different variations of these models allow for bubbles that burst with some probability or bubbles that grow stochastically, one robust implication of all rational bubbles is that, as long as the bubble continues, the price of the asset has to grow explosively. The explosive nature of the price path is consistent with the observed run-up phases to many financial crises. It has also been the focus of much of the empirical literature that attempts to test for the existence of bubbles.

More formally, rearranging the definition of the (net) return, $r_{t+1, s}:=\left(p_{t+1, s}+d_{t+1, s}\right) / p_{t}-$ 1 , where $p_{t, s}$ is the price and $d_{t, s}$ is the dividend payment at time $t$ and state $s$, and taking rational expectations yields

$$
p_{t}=E_{t}\left[\frac{p_{t+1}+d_{t+1}}{1+r_{t+1}}\right]
$$

Hence, the current price is just the discounted expected future price and dividend payment in the next period. For simplicity, assume that the expected return that the marginal rational trader requires in order to hold the asset is constant over time, $E_{t}\left[r_{t+1}\right]=r$, for all $t$. Solving the above difference equation forward and using the law of iterated expectations, one obtains

$$
p_{t}=E_{t}\left[\sum_{\tau=1}^{T-t} \frac{1}{(1+r)^{\tau}} d_{t+\tau}\right]+E_{t}\left[\frac{1}{(1+r)^{T-t}} p_{T}\right] \text {. }
$$

This means that the equilibrium price is given by the expected discounted value of the future dividend stream paid from $t+1$ to $T$ plus the expected discounted value of the price at time $T$. For securities with finite maturity, the price after maturity, say $T$, is zero, $p_{T}=0$. Hence, the price of the asset, $p_{t}$, is unique and simply coincides with the expected future discounted dividend stream until maturity. For securities with infinite 
maturity, $T \rightarrow \infty$, the price $p_{t}$ only coincides with the future expected discounted future dividend stream, call it fundamental value, $v_{t}$, if the so-called transversality condition, $\lim _{T \rightarrow \infty} E_{t}\left[\frac{1}{(1+r)^{T}} p_{t+T}\right]=0$, holds. Without imposing the transversality condition, $p_{t}=v_{t}$ is only one of many possible prices that solve the above expectational difference equation (1). Any price $p_{t}=v_{t}+b_{t}$, decomposed in the fundamental value, $v_{t}$, and a bubble component, $b_{t}$, such that

$$
b_{t}=E_{t}\left[\frac{1}{(1+r)} b_{t+1}\right] \text {, }
$$

is also a solution.

Equation (3) highlights that the bubble component $b_{t}$ has to grow in expectation at a rate of $r$. This insight was used by Blanchard and Watson (1982) in their model of rational bubbles, in which the bubble persists in each period only with probability $\pi$ and bursts with probability $(1-\pi)$. Since in expectation the bubble has to grow at rate $r$, conditional on the bubble surviving it now has to grow at rate $(1+r) / \pi$. As long as the bubble survives, it thus has to grow explosively. More generally, the bubble component may be stochastic. A specific example of a stochastic bubble is an intrinsic bubble, where the bubble component is assumed to be deterministically related to a stochastic dividend process (Froot and Obstfeld (1991)).

The fact that any rational bubble has to grow at an expected rate of $r$ eliminates many potential rational bubbles through a backward-induction argument. For example, a positive bubble cannot emerge if there is an upper limit on the size of the bubble. If, for instance, the presence of substitutes limits the potential bubble in a certain commodity, no bubble can emerge. An ever-growing commodity bubble would make the commodity so expensive that it would be substituted with some other good. Similarly, a bubble on a non-zero supply asset cannot arise if the required return $r$ exceeds the growth rate of the economy, since the bubble would outgrow the aggregate wealth in the economy. Hence, rational bubbles can only exist in a world in which the required return is lower than or equal to the growth rate of the economy. As we discuss below, this can be the case in an overlapping generations (OLG) setting if there is an overaccumulation of private capital that makes the economy dynamically inefficient.

The rational bubble model also shows that a negative bubble, $b_{t}<0$, cannot arise on a limited liability asset. The reason is that a growing negative bubble would imply that, conditional on the bubble surviving, the asset price would have to become negative at some point in the future, which is not possible for a limited liability asset. Moreover, 
if bubbles can never be negative, this also implies that if a bubble vanishes at any point in time, it has to remain zero forever from that point onwards. This leads to the important insight that bubbles cannot start within a rational bubble model; they must already be present when the asset starts trading.

Despite its appeal, the rational bubble model outlined above suffers from the shortcoming that such bubbles can often be ruled out using a general equilibrium zero-sum argument. Specifically, if it is commonly known that the initial allocation in an economy is interim Pareto efficient, then rational bubbles cannot arise (Kreps (1977), Tirole (1982)). To see this, note that if there were a bubble, this would make a seller of the "bubble asset" better off, which-because of the interim Pareto efficiency of the initial allocation - has to make the buyer of the asset worse off. Hence, no individual would be willing to buy the overpriced asset.

This zero-sum argument also holds in a setting in which investors have differential/asymmetric information (as long as agents have common priors). In asymmetric information settings with common priors, a condition for a bubble to exist is that the bubble is not commonly known (see Brunnermeier (2001)). For example, everybody may know that the price of an asset exceeds the value of any possible dividend stream, but this may not be common knowledge, i.e., not everybody knows that all the other investors also know this fact. This lack of higher-order mutual knowledge makes it possible for finite bubbles to exist under the following necessary conditions, given by Allen, Morris, and Postlewaite (1993): (i) It cannot be common knowledge that the initial allocation is interim Pareto efficient, as mentioned above. That is, there have to be gains from trade or at least some investors have to think that there might be gains from trade. (ii) Investors have to remain asymmetrically informed even after inferring information from prices and net trades. This implies that prices cannot be fully revealing. (iii) Investors must be constrained from (short) selling their desired number of shares in at least one future contingency for finite bubbles to persist. In a similar setting, Morris, Postlewaite, and Shin (1995) show that, in finite horizon settings, the size of a bubble can be bounded by the "depth" of knowledge of the bubble's existence. Intuitively, the depth of knowledge measures how far away the agents in the economy are from common knowledge. Conlon (2004) provides a tractable finite-horizon setting to show that bubbles can persist even if everybody knows that everybody knows that the asset is overpriced, but not ad infinitum (i.e., the bubble mutually known at the $n^{\text {th }}$ order, but not commonly known). More broadly, this line of research highlights that, in addition to asymmetric information, frictions, such as short-sale constraints or trading 
restrictions, are needed for bubbles to persist.

\subsection{OLG Frictions and Market Incompleteness}

A well-known example of a bubble that can survive because of a friction inherent in the structure of the underlying economic model is fiat money in an overlapping generations (OLG) model (Samuelson (1958)). While the intrinsic value of fiat money is zero, it can have a positive price in equilibrium. This bubble asset (money) is useful because it can serve as a store of value and thus allows wealth transfers across generations. Absent the bubble asset, this type of wealth transfer is not possible in the OLG framework.

Diamond (1965) develops an OLG model in which capital serves as a store of value. In competitive equilibrium, the interest rate equals the marginal productivity of capital. According to the golden rule, under the optimal allocation, the marginal productivity of capital equals the population growth rate. Diamond (1965) shows that this is not necessarily the case in his OLG framework. For example, capital accumulation can exceed the golden rule, such that the marginal productivity of capital is lower than the population growth rate. The economy is thus dynamically inefficient $]^{3}$ In this case government debt can be used to crowd out excess investment and restore efficiency.

Tirole (1985) shows that, instead of government debt, a bubble on capital can achieve the same objective. Bubbles can exist in this framework because the initial allocation is not Pareto efficient, such that the bubble can lead to a Pareto improvement in the allocation. Note, however, that this happens because the bubble crowds out investment. The presence of a bubble is thus associated with lower investment, while the bursting of a bubble is associated with an investment boom. In practice, we often see the opposite.

A more recent strand of literature deals with these counterfactual implications by adding borrowing constraints. For example, in the model of Martin and Ventura (2012), entrepreneurs can borrow only a fraction of their future firm value. Once financing constraints are present, bubbles not only have a crowding out effect, but can also have a "crowding-in" effect, and thus allow a productive subset of entrepreneurs to increase investments. Because of this crowding-in effect, bubbles can exist and increase efficiency even if the economy absent the bubble is dynamically (constrained) efficient. As in Tirole (1985), bubbles still crowd out total investment since they use up part

\footnotetext{
${ }^{3}$ However, Abel, Mankiw, Summers, and Zeckhauser (1989) argue that it is not clear that this is the case in the U.S.
} 
of savings, but a bubble also relaxes the borrowing constraint for entrepreneurs with good investment opportunities. This improves the flow and allocation of funds to the productive entrepreneurs and crowds in their productive investment.

While in OLG models individuals save for future periods with low (deterministic) endowments, in Bewley-type economies individuals save for precautionary reasons in order to self-insure against uninsurable idiosyncratic risk. Not surprisingly, the implications of these models are similar to those of an OLG setting. In the endowment economy of Bewley $(1977,1980,1983)$, agents self-insure against idiosyncratic risk because they may hit a borrowing constraint in the future. Assets with high market liquidity that pay off without large discounts in all states of the world trade at a "bubble premium." As in OLG models, a bubble in the form of fiat money (or government debt) can improve welfare. In the spirit of Diamond (1965), Aiyagari (1994) introduces capital accumulation with production into a Bewley economy. In this case, precautionary saving, rather than the OLG structure in Diamond (1965), leads to excessive capital accumulation.

The "noise trader risk" model by DeLong, Shleifer, Summers, and Waldmann (1990) also relies on an OLG structure. However, this model focuses on relative prices of two assets with identical (deterministic) cash flow streams. Rational risk averse arbitrageurs with finite horizons are reluctant to take on positions that fully equate both prices since the mispricing may widen further due to irrational noise traders. As a consequence, arbitrageurs only partially trade against the mispricing. In this model, it is thus the combination of short horizons, risk aversion, and noise trader risk that allows the bubble to persist.4 In Dow and Gorton (1994), mispricings may also persist because of short horizons. However, in their model it is not irrational noise traders who prevent arbitrage. Rather risk-neutral arbitrageurs with private information about the future value of an asset have short horizons and only trade against longer-term arbitrage opportunities if it is sufficiently likely that other arbitrageurs receive the same information in the future, such that they can "take over the trade" in future periods, thus forming an "arbitrage chain."

Rational bubbles in the spirit of Blanchard and Watson (1982) or Tirole (1985) rely crucially on an infinite horizon setting. Absent an infinite horizon, bubbles would be ruled out by backward-induction arguments. However, DeMarzo, Kaniel, and Kremer (2008) show that bubbles can also develop in finite horizon OLG models. In the model,

\footnotetext{
${ }^{4}$ Loewenstein and Willard (2006) point out that another important assumption in DeLong, Shleifer, Summers, and Waldmann (1990) is that the risk-free storage technology is available in infinite amounts. If it is not, the mispricing can be ruled out via backward induction.
} 
generations of investors form different cohorts, and markets are incomplete because unborn investors cannot trade with current generations. This leads to a pecuniary externality that creates endogenous relative wealth concerns among agents. The intuition is that, within a generation, the utility of one agent depends on the wealth of other agents. Specifically, when other investors in a cohort are wealthy in middle age, they drive up asset prices and thus make it more costly to save for retirement. This can induce herding behavior: Agents may want to imitate the portfolio choices of other agents in their cohort in order to avoid being poor when others are wealthy. Because of the OLG structure, these relative wealth concerns cannot be eliminated through prior trade. While future young investors benefit from the reduction in their borrowing costs that results when their current middle-aged cohort is wealthy, they are not present when the middle-aged were young.

Relative wealth concerns make trading against the crowd risky and can generate incentives for agents to herd into the risky asset, thus driving up its price. Intuitively, investors are willing to buy an overpriced asset in order not to be priced out of the market in the next period. DeMarzo, Kaniel, and Kremer (2008) show that, when investors are sufficiently risk averse, the risky asset can have a negative risk premium in equilibrium even though its cash flow is positively correlated with aggregate risk.

\subsection{Informational Frictions}

Rational traders may fail to lean against and eliminate an emerging bubble because doing so can be risky. This risk can take different forms. First, there is fundamental risk: The fundamental value may jump unexpectedly, justifying the high price. In this case, investors that trade against the bubble turn out to be "wrong" and lose money. Second, even if investors that lean against the bubble are "right," they may lose money if the price of the asset temporarily rises further, temporarily widening the mispricing, as in the paper by DeLong, Shleifer, Summers, and Waldmann (1990) discussed above. Another class of frictions that allows bubbles to persist are informational frictions. In Abreu and Brunnermeier (2003), long-lived risk-neutral traders even find it optimal to temporarily ride the bubble in order to profit from price increases in the bubble asset. By doing so, they delay the bursting of the bubble. This allows the bubble to grow even larger, leading to a more sizable price correction at a later point in time. Unlike in DeLong, Shleifer, Summers, and Waldmann (1990), it is not the uncertainty about the behavior of irrational noise traders, but uncertainty about the other rational 
traders that makes it optimal to ride the bubble. The key element of the model is that in addition to the competitive preemptive force to exit before others exit and thereby burst the bubble, there is also an element of coordination (or synchronization) among the rational traders. A single trader alone cannot bring down the bubble; a group of them has to be disinvested at the same time in order to burst the bubble.

More specifically, in Abreu and Brunnermeier (2003), the price increase is initially supported by an increase in fundamental value. This is illustrated in Figure 1, where the fundamental value of the asset rises until $t=110$. Kindleberger (1978) refers to this initial phase prior to a bubble as the displacement period, during which the fundamental value of a new technology is learned slowly. The bubble phase starts in period $t=110$, when the price of the asset continues to grow even though there is no further increase in fundamental value. Abreu and Brunnermeier (2003) assume that, from that point onwards, individual traders become sequentially aware that the price is too high. In the example depicted in Figure 1, the first trader thus learns that there is a bubble at $t=110$, while the last trader only learns that there is a bubble at $t=140$. The key assumption is that each trader does not know when, relative to other traders, he learns about the bubble. Thus, from an individual investor's perspective, the starting point and size of the bubble are unknown. As a result, a trader who learns of the bubble at $t=110$ has a lower estimate of the fundamental (or, equivalently, he estimates an earlier starting point of the bubble) than traders who learn of the bubble at a later point in time.

Because of this sequential awareness, it is never common knowledge that a bubble has emerged. It is this lack of common knowledge that removes the bite from the standard backward-induction argument that rules out bubbles. Since there is no commonly known point in time from which one could start backward induction, even finite horizon bubbles can persist.

A synchronization problem arises because Abreu and Brunnermeier (2003) assume that no single trader alone can burst the bubble. This leads to a situation where each trader tries to preempt the crash while attempting to ride the bubble as long as possible. If he attacks the bubble too early, he forgoes profits from the subsequent run-up; if he attacks too late and remains invested in the bubble asset, he suffers from the eventual crash. In equilibrium, each trader finds it optimal to ride the bubble for a certain number of periods, which in turn prolongs the life span of the bubble and justifies riding the bubble even longer. In Abreu and Brunnermeier (2003), it is critical that the selling pressure of a single trader is not fully reflected in the price process. Doblas-Madrid 


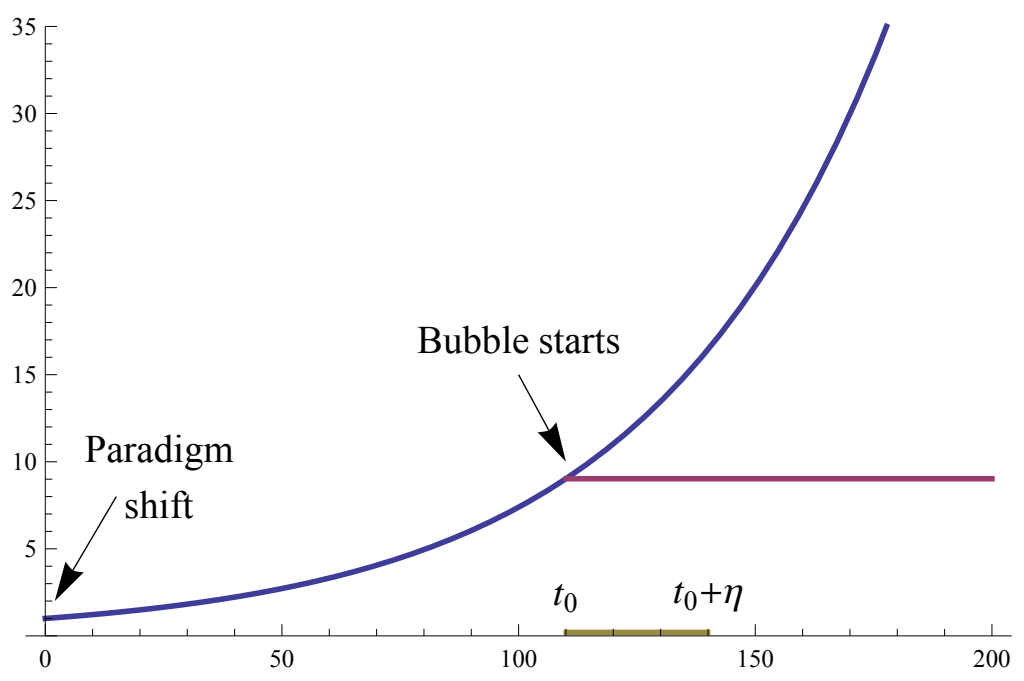

Figure 1: Explosive bubble path and sequential awareness in the model of Abreu and Brunnermeier (2003).

(2012) endogenizes the price process in a discretized setting with multidimensional uncertainty and shows that, as the amount of noise in the economy increases, larger bubbles become possible, since a greater number of agents are able to sell before the crash.

Empirically, there is evidence in favor of the hypothesis that sophisticated investors find it optimal to ride bubbles. For example, between 1998 and 2000, hedge funds were heavily invested in technology stocks (Brunnermeier and Nagel (2004)). Contrary to the efficient-market hypothesis, hedge funds were thus not a price-correcting force during the technology boom, even though they are arguably closer to the ideal of "rational arbitrageurs" than any other class of investors. Similarly, Temin and Voth (2004) document that Hoare's Bank was profitably riding the South Sea bubble in 17191720, even though it had given numerous indications that it believed the stock to be overvalued. Many other investors, including Isaac Newton, also tried to ride the South Sea bubble, but with less success. Frustrated with his trading experience, Newton concluded: "I can calculate the motions of the heavenly bodies, but not the madness of people."

Another important message of the theoretical work on synchronization risk is that relatively insignificant news events can trigger large price movements, because even unimportant news events can allow for traders to synchronize their selling strategies. Indeed, empirically, most large stock price movements cannot be attributed to signif- 
icant fundamental news, according to Cutler, Poterba, and Summers (1989) and Fair (2002). We will return to this feature later when discussing the various triggers of a crisis.

\subsection{Delegated Investment and Credit Bubbles}

Most investors do not just invest their own funds. Rather, they finance their trades by raising equity or debt, or they may simply be in charge of investing other people's money. Delegated investment can lead to further incentive distortions, especially when the ultimate providers of funds are unsure about the skills of the fund manager. As a result, portfolio managers may act myopically, or they might buy "bubble assets" to pretend that they are skilled. If the investors are funded by debt, their incentives may also be distorted by limited liability.

Shleifer and Vishny (1997) stress that delegated portfolio management leads to short-termism and fund managers refraining from exploiting long-run arbitrage opportunities. Fund managers are concerned about short-run price movements, because temporary losses lead to fund outflows. A temporary widening of the mispricing and the subsequent outflow of funds forces fund managers to unwind their positions exactly when the mispricing is the largest. Anticipating this possible scenario, mutual fund managers trade less aggressively against the mispricing. Similarly, hedge funds face a high flow-performance sensitivity, despite some arrangements designed to prevent outflows (e.g., lock-up provisions).

Allen and Gorton (1993) show that fund managers may have an incentive to buy an overvalued asset because not trading would reveal to their client investors that they have low skill and no talent to spot undervalued assets. Consequently, bad fund managers "churn bubbles" at the expense of their uninformed client investors. Because of limited liability, fund managers participate in the potential upside of a trade but not in the downside, such that a classic risk-shifting problem arises. Importantly, delegated investing becomes a positive-sum game for bad fund managers, thus overcoming the zero-sum argument that usually rules out the existence of bubbles. In equilibrium, good managers subsidize bad managers and investors on average earn their cost of investment. With a finite set of portfolio managers, the question remains why the last portfolio manager has an incentive to purchase the asset, a problem that could cause the whole construction to unravel. The model resolves this problem by using a stochastic sequential awareness structure in which the last trader believes that she might with 
some probability be the penultimate trader.

Sato (2009) incorporates delegated investment with relative performance evaluation of fund managers into the framework of Abreu and Brunnermeier (2003) and shows that the incentives to ride a bubble rather than correct the mispricing are even more pronounced than in the original Abreu-Brunnermeier setting.

Allen and Gale (2000a) provide a model for a credit bubble that is based on a riskshifting argument. In this model, investors borrow money from banks in order to invest in a risk-free and a risky asset. By assumption, this borrowing takes the form of debt financing. The lending banks cannot control how investors allocate the funds between the risky and the risk-free asset. Once investors have borrowed money from banks, they thus maximize the value of their levered portfolio, taking into account that they have limited liability when the value of their investment falls such that they cannot repay their loan to banks. In that case, investors simply default and walk away.

Allen and Gale (2000a) show that the equilibrium price of the risky asset exceeds the equilibrium price in an economy in which the same amount of funds is invested directly, such that no risk-shifting problem exists. In this sense, the model predicts that investment financed by credit can lead to bubbles. In an extension of the model, Allen and Gale also show that the uncertainty about future credit conditions can have a similar effect on the price of the risky asset. An important assumption of their model is that banks cannot invest directly. For example, if banks could invest directly in the risk-free asset, they would strictly prefer this over lending to the investors.

More generally, once a bubble is under way, risk shifting may lead to further distortions. For example, when fund managers realize that they are under water because they invested in an overpriced asset they may have incentives to "double down" or "gamble for resurrection." By the classic intuition from Jensen and Meckling (1976), these incentives are particularly strong when the overpriced asset is volatile. Gambling for resurrection, while rational from an individual fund manager's perspective, may prolong the bubble and exacerbate its detrimental effects.

There are other models of inefficient credit booms; yet in those models it becomes harder to determine whether one can refer to these credit booms as bubbles. Lorenzoni (2008) develops an economy in which investors face credit constraints. In equilibrium, there is too little borrowing relative to the first-best allocation, but too much borrowing relative to the constrained efficient second-best allocation. The reason for this effect is a pecuniary externality. When investors choose how much they borrow, they take prices as given and thus do not internalize the effect of their borrowing decisions on the 
tightness of financial constraints during crises. We discuss these models in more detail in the section on crises.

\subsection{Heterogeneous-Beliefs Bubbles}

Another class of models relies on heterogeneous beliefs among investors to generate bubbles. In these models, investors' beliefs differ because they have different prior belief distributions, possibly due to psychological biases. For example, if investors are overconfident about the precision of signals they receive, this leads to different prior distributions (with lower variance) about the signals' noise term. Investors with noncommon priors can agree to disagree even after they share all their information. Also, in contrast to an asymmetric information setting, investors do not try to infer other traders' information from prices.

Combining such heterogeneous beliefs with short-sale constraints can result in overpricing 5 The reason is that optimists push up the asset price, while pessimists cannot counterbalance it because they face short-sale constraints (Miller (1977)). Ofek and Richardson (2003) link this argument to the internet bubble of the late 1990s.

In a dynamic model, the asset price can even exceed the valuation of the most optimistic investor in the economy. This is possible, since the currently optimistic investors (the current owners of the asset) have the option to resell the asset in the future at a high price whenever they become less optimistic. At that point other traders will be more optimistic and thus willing to buy the asset (Harrison and Kreps (1978)). Also in these models, it is essential that less optimistic investors, who would like to short the asset, are prevented from doing so through a short-sale constraint. This means that heterogeneous-beliefs models are more applicable to markets where short selling is difficult, such as real estate, art, or certain stocks for which short selling is either restricted or difficult owing to institutional constraints. Morris (1996) considers a special case of Harrison and Kreps (1978) where traders initially have heterogeneous beliefs, but their beliefs converge over time. As a consequence, an initial bubble component dies out over time (for example, as investors learn after an IPO).

Figure 2 provides a simple example to illustrate how heterogeneous beliefs coupled with the ability to retrade can lead to prices that exceed even the valuation of the most optimistic agent in the economy. In the example there are two traders, $A$ and

\footnotetext{
${ }^{5}$ For more detail on this literature, good starting points are the survey articles by Hong and Stein (2007) and Xiong (2012).
} 
$B$ with heterogeneous beliefs $\pi^{A}$ and $\pi^{B}$, respectively. Both traders value the asset at $E_{0}^{A}[v]=E_{0}^{B}[v]=50$ if they have to hold it until $t=2$. However, if they have the option to resell the asset in $t=1$, this changes. Trader $B$ now anticipates that he can sell the asset to investor $A$, in the up-state $u$, where investor $A$ is an optimist. Vice versa, $A$ expects to sell the asset to $B$ in the down-state $d$, where $B$ is an optimist. Taking into account this option to resell, both investors are willing to pay $p_{0}=57.5$ at time $t=0$, even though they both expect the asset to pay off only 50 . The price of the asset thus exceeds even the most optimistic agent's valuation of the asset.

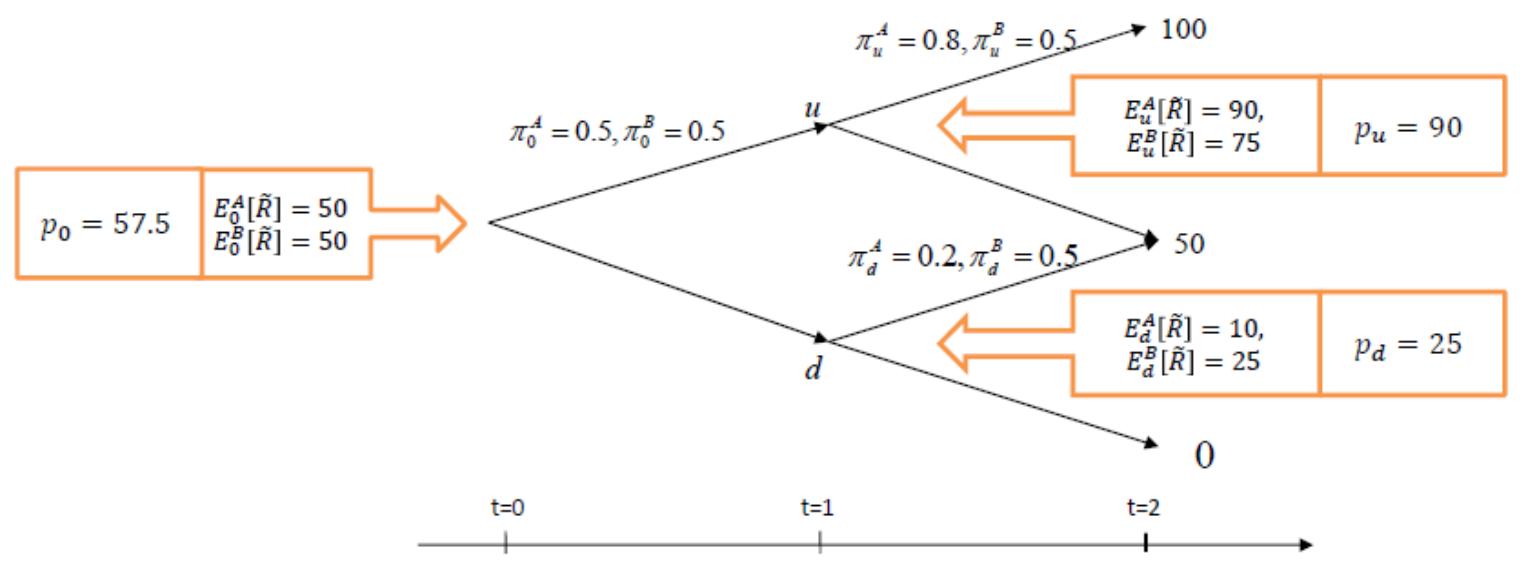

Figure 2: A simple example economy with heterogeneous beliefs.

An attractive feature of heterogeneous-beliefs bubbles is that they predict that bubbles are accompanied by large trading volume and high price volatility, as, for example, in the model of Scheinkman and Xiong (2003). $]^{6}$ If investors are risk averse, another prediction of heterogeneous-beliefs models is that the size of the bubble, trading volume, and volatility are decreasing in the supply (tradeable asset float) of the bubble asset (Hong, Scheinkman, and Xiong (2006)). These predictions are consistent with the evidence from the internet stock bubble in the late 1990s, which was associated with high trading volume and high price volatility. Also consistent with heterogeneous-beliefs models is the observation that the internet bubble started to deflate from March 2000

\footnotetext{
${ }^{6}$ For models of trading volume based on heterogeneous beliefs, see also Harris and Raviv (1993).
} 
onwards, as the tradeable float of internet stocks increased (see Ofek and Richardson (2003)). Chen, Hong, and Stein (2001) also document that high trading volume relative to trend forecasts negative skewness (future crashes), consistent with the heterogeneousbeliefs model put forward in Hong and Stein (2003).

A number of papers also explore the role of credit in heterogeneous-beliefs models. Geanakoplos (2010) develops a model in which agents with heterogeneous beliefs have limited wealth, such that agents with optimistic views about an asset borrow funds from more pessimistic agents, against collateral. The extent to which pessimistic agents are willing to finance the investment by optimistic agents then becomes an important determinant of leverage and, in turn, asset prices. Moreover, in downturns, when optimists lose wealth, more of the asset has to be held by pessimists, thus exacerbating price declines. In contrast to models in the spirit of Harrison and Kreps (1978), in this setup beliefs do not change over time, such that no resell premium arises. Hence, the price of the asset always remains below the valuation of the most optimistic agent. Simsek (2011) shows that the extent to which pessimists are willing to finance asset purchases by optimists depends on the specific form of the belief disagreement. Intuitively speaking, when disagreement is mostly about the upside, pessimists are more willing to provide credit than when disagreement is about the downside. Hence, it is not just the amount of disagreement, but also the nature of disagreement among agents that matters for asset prices. Fostel and Geanakoplos (2012) provide a model in which financial innovation in the form of tranching raises asset prices by increasing the ability of the optimist to take positions in the asset. At the same time, in their model an unexpected introduction of credit default swaps can lead to drastic reductions in asset prices, since it allows pessimists to more effectively bet against the bubble asset. This echoes the argument in Gorton (2010) that the introduction of the ABX index on subprime securitization transactions contributed to the dramatic bust in the subprime mortgage market.

The zero-sum argument that typically rules out bubbles does not apply to a setting with heterogenous beliefs since each trader thinks that he benefits from future trading. However, these beliefs are not mutually consistent. From any individual trader's perspective, his trading causes a negative externality on his counterparty. Based on this, Brunnermeier, Simsek, and Xiong (2012) develop a welfare criterion for settings with heterogeneous beliefs. Under this criterion, trading by market participants with heterogeneous beliefs leads to an inferior allocation if this trading lowers overall expected social welfare under any of the traders' subjective probability measures. 


\subsection{Empirical Evidence on Bubbles}

Identifying bubbles in the data is a challenging task. The reason is that in order to identify a bubble, one needs to know an asset's fundamental value, which is usually difficult to measure. Based on this, a number of scholars have argued that certain episodes that are often referred to as bubbles may in fact have fundamental explanations. For example, Garber (2000) argues that the Dutch tulip mania, the Mississippi bubble, and the South Sea bubble can in fact be explained based on fundamentals. Pastor and Veronesi (2006) argue that the internet bubble of the late 1990s may be explained without appealing to a bubble logic. More generally, in Pastor and Veronesi (2009), apparent bubbles in stock prices can occur after technological revolutions, if the average productivity of the new technology is uncertain and subject to learning. The apparent "bubble" deflates as the new technology is widely adopted and its risk becomes systematic.

However, there are a number of clean examples of mispricings or bubbles that cannot be explained by fundamental reasons. For example, Lamont and Thaler (2003) use the Palm/3Com carve-out to document a relative mispricing between the share prices of Palm and 3Com that cannot be attributed to fundamental differences. One interpretation is that Palm shares were subject to an irrational internet premium. Xiong and $\mathrm{Yu}$ (2011) provide another clean example from the Chinese warrants market. In this example, the fundamental is the stock price that underlies the warrant and is thus measurable. Xiong and Yu (2011) document that out of-the-money warrants that were essentially worthless were traded heavily at extremely inflated prices.

The main approach of empirical studies that seek to test for the presence of bubbles has been the rational bubble model in the spirit of Blanchard and Watson (1982). Most of these tests rely on the explosive feature of the (conditional) bubble path in the rational bubble model.

In an early study, Flood and Garber (1980) use the result that bubbles cannot start within a rational asset pricing model. This means that, at any point in time, the price of an asset affected by a bubble must have a non-zero part that grows at an expected rate of $r$. However, this approach is problematic because of an exploding regressor problem. As the bubble grows over time, the regressor explodes such that the coefficient estimate relies primarily on the most recent data points. This leads to a small sample problem, because the ratio of the information content of the most recent data-point to the information content of all previous observations never goes to zero. 
Hence, the central limit theorem does not apply.

In Diba and Grossman (1988), the approach taken is to examine whether the difference between the stock price and the price dividend ratio is stationary, which should be the case under the hypothesis that there is no bubble. If the dividend process follows a linear unit-root process (e.g., a random walk), then the price process also has a unit root. However, the difference between the price and the discounted expected dividend stream, $p_{t}-d_{t} / r$, is stationary under the no-bubble hypothesis (in econometric language, $p_{t}$ and $d_{t} / r$ are co-integrated). Using a number of unit root tests, autocorrelation patterns, and co-integration tests, Diba and Grossman conclude that the no-bubble hypothesis cannot be rejected.

However, this study has also been challenged on econometric grounds. In particular, Evans (1991) shows that the standard linear econometric methods used in the study by Diba and Grossman may fail to detect the explosive non-linear patterns of bubbles that collapse periodically. West (1987) proposes a different approach that relies on estimating the parameters needed to calculate the expected discounted value of dividends in two different ways. His insight is that only one of the two estimates is affected by the bubble. First, the accounting identity (1) can be rewritten as $p_{t}=\frac{1}{1+r}\left(p_{t+1}+d_{t+1}\right)-\frac{1}{1+r}\left(p_{t+1}+d_{t+1}-E_{t}\left[p_{t+1}+d_{t+1}\right]\right)$. This means that when running an instrumental variables regression of $p_{t}$ on $\left(p_{t+1}+d_{t+1}\right)-\mathrm{using}$, for example, $d_{t}$ as an instrument - one obtains an estimate for $r$ that is independent of the existence of a rational bubble. Second, if (for example) the dividend process follows a stationary $\operatorname{AR}(1)$ process, $d_{t+1}=\phi d_{t}+\eta_{t+1}$, with independent noise $\eta_{t+1}$, one can estimate $\phi$. The expected discounted value of future dividends is then given by $v_{t}=\frac{\phi}{1+r-\phi} d_{t}$. Under the null hypothesis that there is no bubble, i.e., $p_{t}=v_{t}$, the coefficient estimate of the regression of $p_{t}$ on $d_{t}$ thus provides a second estimate of $\frac{\phi}{1+r-\phi}$. West then uses a Hausman-specification test to determine whether both estimates coincide. He finds that the U.S. stock market data usually reject the null hypothesis of no bubble.

\subsection{Experimental Evidence on Bubbles}

In addition to empirical tests, researchers have used controlled laboratory experiments to study bubbles.7 The advantage of laboratory experiments is that they allow the researcher to isolate and test specific mechanisms and theoretical arguments. One main line of research in this area is concerned with backward induction, which is one

\footnotetext{
${ }^{7}$ For a survey of the early work on experimental asset markets, see Sunder (1995).
} 
of the classic theoretical arguments to rule out bubbles.

Many studies in this literature rely on the classic centipede game of Rosenthal (1981). In this game, two players alternately decide whether to continue or stop a game that runs for a finite number of periods. By construction, at any point in time the player making the move is better off stopping the game than continuing if the other player stops immediately afterwards, but he is worse off stopping than continuing if the other player continues afterwards. Using backward induction, this game has only a single subgame perfect equilibrium: The first player to move should immediately stop the game. In experimental settings, however, players usually initially continue to play the game, which is a violation of the backward-induction principle (see, for example, McKelvey and Palfrey (1992)). These experimental findings thus question the validity of the theoretical backward-induction argument that is often used to rule out bubbles.

Another line of research (Smith, Suchanek, and Williams (1988)) directly studies settings in which participants in the experiment can trade a risky asset. All participants know that the asset pays a uniformly distributed random dividend of $d \in\left\{d_{0}=0, d_{1}, d_{2}, d_{3}\right\}$ in each of the 15 periods. Hence, the fundamental value for a risk-neutral trader is initially $15 \sum_{i} \frac{1}{4} d_{i}$ and then declines by $\sum_{i} \frac{1}{4} d_{i}$ in each period. The study finds that there is vigorous trading, and prices initially rise despite the fact that it is known to all participants that the fundamental value of the asset steadily declines. The time series of asset prices in these experiments often exhibits a classic boom-bust pattern. An initial boom phase is followed by a period during which the price exceeds the fundamental value, before the price collapses towards the end. One interpretation of these results is that bubbles emerge because each trader hopes to pass the asset on to some less rational trader (greater fool) in the final trading rounds. However, similar patterns also emerge when investors have no resale option and are forced to hold the asset until the end (Lei, Noussair, and Plott (2001)). Kirchler, Huber, and Stöckl (2011) argue that the bubbles documented by Smith, Suchanek, and Williams (1988) are due to the combination of declining fundamental value (which leads to mispricing) and an increasing cash-to-asset-value ratio (which leads to overvaluation) 8 Brunnermeier and Morgan (2010) experimentally test the predictions of Abreu and Brunnermeier (2003) and document that subjects are reluctant to attack a bubble if they become sequentially

\footnotetext{
${ }^{8}$ The experimental setting of Smith, Suchanek, and Williams (1988) has generated a large follow-up literature that documents the robustness of their findings (see, for example, King, Smith, Williams, and Van Boening (1993), Van Boening, Williams, and LaMaster (1993), Porter and Smith (1995), Dufwenberg, Lindqvist, and Moore (2005), Haruvy and Noussair (2006), and Haruvy, Lahav, and Noussair (2007)).
} 
aware of the bubble and don't know which position in the queue they are. In a related setting, Moinas and Pouget (2012) provide an elegant experimental design to show that the propensity to speculate increases with the (potentially infinite) trading horizon and that a heterogeneous quantal response equilibrium provides a good description of the experimental outcome.

\section{Crises}

A sustained run-up phase of low risk premia is typically followed by a crisis. Intuitively speaking, imbalances that build up during the boom phase suddenly materialize, often with a vengeance. Paradoxically, it is thus a low-volatility environment that is the breeding ground for the high volatility that follows when the crisis erupts.

For most crises it is difficult to pinpoint the exact trigger that acts as the catalyst. Even when we can point towards a potential trigger, in many cases the triggering event to which a crisis is attributed seems small relative to the crisis that follows. For example, some people attribute the bursting of the internet bubble to the announcement that the human genome project could not be patented. Others attribute it to the enormous rate at which some internet companies were burning cash, while others dismiss all of these potential triggers. For the more recent housing bubble, the triggering event seems clearer. Blame is usually laid on the subprime mortgage market that began to turn sour in late 2006. However, the subprime market constituted only about $4 \%$ of the overall mortgage market. This leads to the question, how can such "small" news cause so much damage? And how can a crisis that originates in the subprime mortgage market propagate across so many sectors of the economy?

The reason is amplification. In the presence of amplification, even a modest triggering event can cause large spillovers across the financial system. Amplification can occur because of direct spillovers, such as so-called domino effects, or indirect spillovers that work through prices, constraints, and the endogenous responses of market participants. Conceptually, spillovers are associated with externalities that an individual action $a^{-i}$ causes on the utility or payoff of some other individual $u^{i}\left(a^{i}, a^{-i}\right)$. The marginal externality (the effect of a change in individual $-i$ 's action on individual $i$ 's utility) can

be expressed as $\frac{\partial u^{i}\left(a^{i}, a^{-i}\right)}{\partial a^{-i}}$. Since individual $-i$ does not internalize the impact of her action on individual $i$ 's payoff, the resulting outcome is often not Pareto efficient.

In contrast to the classic textbook externality, in which an action directly affects 
the well-being of another agent, externalities in finance often work through prices. For example, a financial institution may not internalize that the price changes that result from liquidating certain assets will also affect other institutions' balance sheets. In a complete markets Arrow-Debreu economy, these pecuniary externalities do not lead to inefficiencies. In fact, it is precisely the price-taking behavior of agents that ensures that the equilibrium allocation is efficient. The reason is that under complete markets the marginal rates of substitution are equalized in equilibrium, such that a small wealth transfer effected through prices does not affect welfare.

This changes, however, when we leave the complete-markets setup of Arrow-Debreu. In an incomplete-markets setting, marginal rates of substitution are usually not equalized across all agents or time periods, such that wealth transfers through prices can affect efficiency. Since price-taking agents do not internalize this, the resulting equilibrium is usually not even constrained efficient (i.e., a planner subject to the same constraints could improve on the competitive equilibrium allocation). A similar argument holds in economies with occasionally binding constraints that depend on prices.9

Hence, if financial institutions are subject to constraints that depend on asset prices, price-taking financial institutions will fail to internalize the effect of their actions on the tightness of the constraint such that the resulting equilibrium is usually not constrained efficient. As a result, pecuniary externalities have efficiency consequences and the competitive equilibrium generally does not lead to an allocation that is constrained efficient. In the context of financial markets, these pecuniary externalities are sometimes referred to as fire-sale externalities.

Another important phenomenon during financial crises is amplification that arises due to the self-reinforcing nature of market participants' actions. For example, if one financial institution sells and depresses the price, others become more likely to follow suit and destabilize the price even further. Conceptually speaking, during financial crises individual actions often become strategic complements, which formally is the case whenever payoffs satisfy $\frac{\partial^{2} u^{i}\left(a^{i}, a^{-i}\right)}{\partial a^{i} \partial a^{-i}}>0$. When this is the case, demand curves are often upward sloping, such that declining prices lead to a reduction in demand. When this strategic complementarity is strong enough, multiple equilibria can arise.

Moreover, adverse feedback loops and liquidity spirals may arise and amplify the

\footnotetext{
${ }^{9}$ For a more formal treatment, see Hart (1975), Stiglitz (1982), Geanakoplos and Polemarchakis (1986), and Gromb and Vayanos (2002). See Davila (2011) for a distinction between pecuniary externalities due to incomplete markets and pecuniary externalities that work through financial constraints that depend on prices.
} 
crisis. This is the case when the liquidity mismatch of many market participants is high. Liquidity mismatch is high when, on the asset side of the balance sheet, real investment is irreversible (due to technological illiquidity) or the assets can only be sold to others with a large discount in times of crisis (due to market illiquidity) and, at the same time, on the liability side of the balance sheet, the maturity structure is very short term (low funding liquidity). Market liquidity is especially high for flight-to-safety assets, such as gold or U.S. Treasuries. However, the flight-to-safety status can potentially be lost if market participants suddenly stop coordinating on one of the flight-to-safety assets 10

Overall, a key element in understanding financial crises and systemic risk is thus not only direct domino effects, but also spillovers and the endogenous responses of other market participants. These spillovers and endogengous responses lead to increased endogenous risk, which not only amplifies the initial shock but also makes a temporary adverse shock persist. Recovery from the crisis may thus take a long time.

Understanding where spillovers and amplification occur is also crucial for policy decisions during financial crises. For example, it is important to identify where in the intermediation chain the externalities and amplification effects are at work. This is the primary reason why policy research has put a lot of emphasis on differentiating between the borrower balance-sheet channel (frictions arise on the borrower's side) and the lender balance-sheet channel (frictions arise on the lending side), both of which we discuss below.

\subsection{Counterparty/Bank Runs}

One important amplification mechanism during financial crises is the potential for creditor or depositor runs. The possibility for runs arises because of the liquidity mismatch inherent in the financial system. Runs may occur as depositor runs on banks, such as the classic 19th-century bank run, but they can also materialize as creditor runs on unsecured short-term credit of financial institutions. For secured, i.e., collateralized funding markets, borrowers may experience so-called margin runs.

The important underlying friction that allows such runs is the presence of liquidity mismatch. While liquidity mismatch serves a valuable function in terms of channeling savings into long-term investment activity, it makes the financial system fragile. The canonical model of such maturity and liquidity transformation is developed in Diamond

\footnotetext{
${ }^{10}$ Liquidity mismatch does not equal maturity mismatch. For example, holding 30-year U.S. Treasuries funded with short-term paper has very little liquidity mismatch but large maturity mismatch.
} 
and Dybvig (1983), building on Bryant (1980). The main insight from these papers is that the institutional structure of maturity transformation makes the intermediary fragile because it creates the possibility of bank runs.

In the Diamond-Dybvig model, banks offer demand deposits that match agents' potential liquidity needs and use a large part of these deposits to finance illiquid longterm investments (maturity transformation). However, these demand deposits open up the possibility of bank runs. More specifically, there are two investment technologies: an illiquid technology and a storage technology. The illiquid technology is a long-run investment project that requires one unit of investment. It can be liquidated early in $t=1$ at a salvage value of $L \leq 1$. If carried through until $t=2$, the long-run technology pays off a fixed gross return of $R>1$. In addition to the productive long-run investment project, agents also have access to a costless storage technology. Agents can invest a fraction of their endowment in the illiquid investment project and store the rest. The savings opportunities can thus be summarized as:

\begin{tabular}{|l|c|c|c|}
\hline Investment Projects & $t=0$ & $t=1$ & $t=2$ \\
\hline Risky investment project & & & \\
- continuation & -1 & 0 & $R>1$ \\
- early liquidation & -1 & $L \leq 1$ & 0 \\
Storage technology & & & \\
- from $t=0$ to $t=1$ & -1 & +1 & \\
- from $t=1$ to $t=2$ & & -1 & +1 \\
\hline
\end{tabular}

There is a continuum of ex-ante identical agents who receive an endowment of one unit at $t=0$. Each agent faces a preference shock prior to $t=1$. Depending on this shock, the agent consumes either in $t=1$ ("impatient consumers") or in $t=2$ ("patient consumers"). Impatient consumers derive utility $U^{1}\left(c_{1}\right)$ only from consumption in $t=1$, whereas patient consumers derive utility $U^{2}\left(c_{2}\right)$ only from consumption in $t=2$. Since the agents do not know ex-ante whether they will be impatient or patient, they would like to insure themselves against their uncertain liquidity needs.

Without financial intermediaries each agent would invest an amount $x$ in the longrun investment project and store the remainder $(1-x)$. Impatient consumers who liquidate their project then consume $c_{1}=x L+(1-x) \in[L, 1]$, while patient consumers consume $c_{2}=x R+(1-x) \in[1, R]$. The ex-ante utility of each agent is given by $\lambda U\left(c_{1}\right)+(1-\lambda) U\left(c_{2}\right)$, where $\lambda$ denotes the probability of becoming an impatient consumer. 
A bank can improve on this allocation by offering a deposit contract $\left(c_{1}^{*}, c_{2}^{*}\right)$, which satisfies

$$
\frac{\partial U}{\partial c_{1}}\left(c_{1}^{*}\right)=R \frac{\partial U}{\partial c_{2}}\left(c_{2}^{*}\right)
$$

such that the agents' ex-ante utility is maximized. This is possible when the banking sector is competitive and when there is no aggregate risk. The bank invests $x^{*}$ in the long-run investment project and stores the remainder $\left(1-x^{*}\right)$. The stored reserves are enough to satisfy the impatient consumers' demand in $t=1$, that is, $\lambda c_{1}^{*}=\left(1-x^{*}\right)$, while the remainder is paid out to patient consumers in $t=2$. Thus, $(1-\lambda) c_{2}^{*}=R x^{*}$. As long as only impatient consumers withdraw their demand deposit $c_{1}$ from the bank in $t=1$, the bank is prepared for this money outflow and does not need to liquidate the long-run asset. In this case, no patient consumer has an incentive to withdraw his money early.11 Hellwig (1994) shows that a similar allocation is possible also in a setting with aggregate interest rate risk in the form of an uncertain short-term return $r_{2}$ from date 1 to date 2 . The main difference is that, in the presence of interest rate risk, it can be optimal to reinvest some of the liquid resources at date 1 when $r_{2}$ turns out to be high.

\subsubsection{Bank Runs as a Sunspot Phenomenon}

However, if patient consumers start withdrawing money early, then the bank does not have enough reserves and is forced to liquidate some of its long-run investments. If the bank promised a payment $c_{1}^{*}>1$, which is optimal if the deposit holders' relative risk aversion coefficient exceeds 1 , the bank has to liquidate more than one unit of the long-run project for each additional patient consumer who withdraws in $t=1$. In fact, if the salvage value $L$ is strictly smaller than 1 , the bank has to liquidate an even larger amount.

Early liquidation of long-term investments reduces the bank's ability to make payments in $t=2$ and thus increases the incentive for patient consumers to withdraw their money early. Specifically, Diamond and Dybvig (1983) assume that the bank must honor a sequential service constraint. Depositors reach the teller one after the other and the bank honors its contracts until it runs out of money. The sequential service

\footnotetext{
${ }^{11}$ An important assumption in the Diamond-Dybvig model is that agents have restricted trading opportunities, in the sense that they cannot trade in a secondary market at the intermediate date. If such trading were possible, financial intermediation can no longer support the optimal allocation because agents would arbitrage the optimal insurance scheme offered by the bank (see Jacklin (1987), Diamond (1997), Farhi, Golosov, and Tsyvinski (2009)).
} 
constraint gives depositors the incentive to withdraw their money as early as possible if they think that patient consumers will also withdraw their demand deposits early and render the bank insolvent. Because of this payoff externality, individual agents' early withdrawal decisions are strategic complements. As a result, there also exists a bank run equilibrium in which all agents immediately withdraw their deposits in $t=1$ and the bank is forced to liquidate its assets. In the Diamond-Dybvig model, both the Pareto inferior bank run equilibrium and the full insurance equilibrium are possible, and which equilibrium is selected is not pinned down by the model. Equilibrium selection may, for example, depend on sunspots, i.e., commonly observed exogenous random variables that serve as a coordination device.

There are a number of ways to eliminate the inferior run equilibrium. Suspension of convertibility eliminates the bank run equilibrium as long as the fraction of impatient consumers $\lambda$ is deterministic. If the bank commits itself to serve only the first $\lambda$ customers who attempt to withdraw their demand deposits, no assets ever need be liquidated, and the bank always has enough money to pay $c_{2}^{*}$. Consequently, patient consumers never have an incentive to withdraw early. If the fraction of impatient consumers $\lambda$ is random, on the other hand, suspension of convertibility does not prevent bank runs, since the bank does not know when to stop paying out money in $t=1$. Deposit insurance can eliminate the bank run equilibrium even for a random $\lambda$. If the deposit guarantee of $c_{1}^{*}$ is nominal, an inflation tax that depends on early withdrawals can reduce the real value of the demand deposit. This eliminates the patient consumers' incentive to withdraw their money early. Finally, banking panics may be prevented if the central bank is willing to act as a lender of last resort. Intuitively, if agents know that the bank can borrow from a lender of last resort and never has to liquidate the long-term investment, there is no reason for patient consumers to run. Bagehot (1873) famously proposed that the lender of last resort should lend to illiquid but solvent institutions, at a penalty rate and against good collateral. Rochet and Vives (2004) formalize this idea using a global games setup (more on this below). Of course, one difficulty with this type of lender-of-last-resort intervention is that in practice it may be difficult to tell apart an illiquid institution from a truly insolvent institution.

\subsubsection{Information-induced Bank Runs}

In the Diamond-Dybvig model, bank runs arise only as sunspot phenomena. One im-

plication is that bank runs may arise at any time, and not necessarily during financial 
crises. However, empirically bank runs seem to be related to fundamental information. For example, Gorton (1988) demonstrates that bank runs usually occur after bad fundamental news about the health of a bank or the financial system.

A number of models analyze the connection between fundamental news and bank runs (e.g., Postlewaite and Vives (1987), Jacklin and Bhattacharya (1988), Chari and Jagannathan (1988), Morris and Shin (2001), Goldstein and Pauzner (2005)). The common theme in these papers is that interim information about the model's parameters transforms a model of multiple equilibria into a model of amplification, in which in the unique equilibrium a bank run occurs with a certain probability. In these models, bank runs usually occur when a fundamental variable crosses a threshold, which means that small changes in the information environment can lead to large changes in behavior and thus precipitous amplification.

For example, in Jacklin and Bhattacharya (1988) the payoff of the long-run investment project $R$ is random and some agents receive information about $R$ prior to their withdrawal decision. In contrast to Diamond and Dybvig (1983), there is a unique equilibrium. In this equilibrium, bank runs occur only in some states of the world. Postlewaite and Vives (1987) develop an alternative framework with a unique information-induced bank run equilibrium for certain parameter values.

The payoff structure in Jacklin and Bhattacharya (1988) differs from Diamond and Dybvig (1983) in two ways. First, the salvage value of the illiquid investment project, $L$, is zero in $t=1$. Second, the final payoff of the illiquid project $R$ is random. The probability of a high return $R_{H}$ is $(1-\theta)$ and the probability of a low return $R_{L}$ is $\theta$. In the latter case, the bank can pay at most a fraction $R_{L} / R_{H}$ of the maximum payment in $t=2$. Agents learn their time preference $\beta$ in $t=1$. A fixed fraction $\alpha$ of the more patient "late consumers" also receive a signal about the payoff of the illiquid project. This signal allows the informed late consumers to update their prior $\theta$ to $\hat{\theta}$. Impatient consumers have a preference to consume early and thus withdraw a large fraction of their deposits from the bank in $t=1$. However, informed patient consumers also withdraw their money early if the posterior probability of the low project payoff $R_{L}, \hat{\theta}$, is above a threshold level $\bar{\theta}$, which triggers a bank run.

Chari and Jagannathan (1988) analyze information-induced bank runs where uninformed late consumers infer information from the aggregate withdrawal rate. In their setup, all agents are risk neutral with a utility function $U^{i}\left(c_{1}, c_{2}\right)=c_{1}+\beta^{i} c_{2}$. Type 1 agents are early consumers and their $\beta^{1}$ is close to zero. Type 2 agents with high $\beta^{2}$ are late consumers. The fraction $\lambda \in\left\{0, \lambda_{1}, \lambda_{2}\right\}$ of impatient early consumers is 
random. As in Jacklin and Bhattacharya (1988), a fraction $\alpha$ of late consumers receive a signal about the random return of the illiquid investment project $R \in\left\{R_{L}, R_{H}\right\}$. However, this fraction is also random with $\alpha \in\{0, \bar{\alpha}\}$. In contrast to Diamond and Dybvig (1983), the authors do not assume the sequential service constraint. In their model all deposit holders arrive simultaneously and there is a pro rata allocation of the funds. If short-term funds are not sufficient, the bank can prematurely liquidate the long-run project. As long as total aggregate withdrawals do not exceed some threshold $\bar{K}$ the salvage value of the long-run investment project is $L=1$. Otherwise, premature liquidation is costly, i.e., $L<1$.

In this model, a large withdrawal of deposits (i) can be due to a large fraction of impatient consumers, that is, a high realization of $\lambda$, or (ii) may occur because informed patient consumers receive a bad signal about $R$. Since uninformed patient consumers cannot distinguish between both forms of shocks, they base their decisions solely on aggregate withdrawals. Hence, uninformed patient consumers might misinterpret large withdrawals due to a high $\lambda$ as being caused by a bad signal received by informed late consumers. This induces them to withdraw their funds and forces banks to liquidate their investment projects. This type of wrong inference by the uninformed deposit holders can lead to bank runs even when $R=R_{H}$. The liquidation costs erode the bank's assets and thus possible payouts in $t=2$. Note that in Chari and Jagannathan (1988), strategic complementarities arise for two reasons: The early withdrawal sends a signal to the uninformed deposit holders that the return of the long-run asset is probably low (information externality) and also forces the bank to conduct costly liquidation (payoff externality) 12

More recently, Morris and Shin (2001) and Goldstein and Pauzner (2005) have used global games techniques to analyze bank run models with unique equilibria. In these models, every agent receives a noisy signal about the return of the long-run project. In the unique equilibrium, bank runs are triggered whenever the realization of the fundamental is below some threshold.

Allen and Gale $(1998,2004)$ extend the original Diamond-Dybvig model by introducing uncertainty about the size of the aggregate preference shock $\lambda$ in addition to uncertainty about the return of the long-term investment $R$. Uncertainty about $R$ introduces the possibility of fundamental bank runs: Depositors may choose to withdraw when $R=R_{L}$. The bank can prevent this run by limiting the amount the depositor

\footnotetext{
${ }^{12}$ In Gorton (1985), a bank can stop a run if $R=R_{H}$. By paying a verification cost, it is able to credibly communicate the true return $R_{H}$ and suspend convertibility.
} 
is allowed to withdraw at date 1 to be less than his consumption at date 2. However, Allen and Gale show that it may actually be preferable not to prevent the bank run when $R=R_{L}$. Allowing the bank run in the low state can raise ex-ante welfare if the loss from early liquidation in response to the bank run in the low state is more than offset by the gains in the high state. For example, this can be the case when the low payoff $R_{L}$ is sufficiently unlikely. One way to interpret this result is that the bank run in the bad state introduces a state contingency that is not possible with a standard deposit contract. Another important implication of this analysis is that, from an exante welfare perspective, bank runs and, more generally, crises need not be inefficient phenomena; they may occur as part of an efficient equilibrium.

When the fraction of early consumers is random, $\lambda \in\left\{\lambda_{H}, \lambda_{L}\right\}$, but banks have to choose the amount invested in the liquid asset ex-ante, this can lead to substantial price volatility. If banks want to hold sufficient liquidity to serve withdrawal demands even in the high liquidity demand state, they will end up holding excess liquidity in the low liquidity demand state. This can be an equilibrium only if the price of the long-term asset is sufficiently low in the high liquidity demand state and sufficiently high in the low liquidity demand state. In other words, an equilibrium where banks hold sufficient liquidity will exhibit significant price volatility. In addition, there may be a mixed-strategy equilibrium with default in which ex-ante identical banks choose different portfolios and offer different deposit contracts. In particular, there are safe banks that choose low values of $d$ and $x$ and never default and there are risky banks that choose high values of $d$ and $x$ and run the risk of default. Overall, we see that in the presence of aggregate risk, equilibria usually exhibit asset price volatility, default of intermediaries, or both.

Another potential amplifying mechanism during crises is the presence of Knightian uncertainty. Caballero and Krishnamurthy (2008) present a model of this phenomenon. The argument is that financial crises may be characterized by Knightian uncertainty about the environment, rather than merely increases in the riskiness of asset payoffs. For example, economic agents may call into question their model of the world once a crisis hits.

As in Diamond and Dybvig (1983), Caballero and Krishnamurthy assume that agents are subject to discount factor shocks. However, unlike in the Diamond-Dybvig model, there are three periods with potentially two waves of discount factor shocks. Agents exhibit max-min behavior relative to the second, more unlikely shock. Individually, all agents prepare for the worst-case, even though collectively it is not possible 
that they are all hit by the worst case scenario. As a result, agents act as if they collectively overestimate the probability of the second more unlikely shock and hold too much liquidity. As in the bank run models discussed above, a central bank could improve welfare (measured under true probabilities, not under the agents' max-min preferences) - for example, by acting as a lender of last resort. Conceptually, Knightian uncertainty and the associated belief distortions in Caballero and Krishnamurthy (2008) play a role similar to the sequential service constraint in Diamond and Dybvig (1983).

In all of the models discussed above, liquidity mismatch is a central element of amplification and propagation of shocks during financial crises. Of course, as seen in our discussion of the canonical Diamond-Dybvig model, maturity transformation is a central and, at least to some extent, a desirable element of financial intermediation. Moreover, in addition to the liquidity provision rationale provided by Diamond and Dybvig (1983), Calomiris and Kahn (1991) and Diamond and Rajan (2001) point out that, in the absence of deposit insurance, short-term financing can serve another positive role: The fragility created by the deposit contract disciplines the intermediary and enables him to raise more funds than an entrepreneur could on his own.

However, given the potential costs of maturity mismatch during crises, an important question is whether the amount of liquidity mismatch that is privately chosen by financial institutions is optimal. Brunnermeier and Oehmke (2012) argue that this may not be the case. In particular, an individual creditor to a financial institution can have an incentive to shorten the maturity of his loan, allowing him to adjust his financing terms or pull out before other creditors can. This, in turn, causes all other creditors to shorten their maturity as well. This dynamic leads to a maturity rat race that is present whenever interim information is mostly about the probability of default rather than the recovery in default. If financial institutions cannot commit to a maturity structure, equilibrium financing may be inefficiently short-term in the sense that the financial institution may use more short-term debt than would be warranted by optimally trading off intermediation and commitment benefits against that resulting financial fragility. In addition, Acharya (2009), Acharya and Yorulmazer (2007, 2008), and Farhi and Tirole (2012) point out that if financial institutions expect authorities to intervene via untargeted bailouts during financial crises, this provides another reason for financial institutions to finance themselves short-term, increase leverage, and load on systemic risk. 


\subsection{Collateral/Margin Runs}

Traditional banks that fund themselves primarily through demand deposits are subject to counterparty bank runs as modelled in Diamond and Dybvig (1983). Modern financial institutions finance themselves to a large extent through wholesale funding markets and securitized lending, like the repo market. These markets are subject to collateral runs via increased margin requirements by financiers, as in Brunnermeier and Pedersen (2009). Collateralized lending can be more anonymous since it is secured by the collateral asset rather than the credibility of the counterparty. Such collateral runs occurred in the asset-backed commercial paper (ABCP) market in 2007 (Acharya, Schnabl, and Suarez (2012)) and in parts of the repo market in 2008 (Gorton and Metrick (2011), Krishnamurthy, Nagel, and Orlov (2011), and Copeland, Martin, and Walker (2010)). These runs can cause spillover and contagion effects because changes in prices lead to losses that depress financial institutions' net worth (equity). Consequently, they are forced to fire-sell assets, which, in turn, further depresses prices and increases losses. This leads to another round of selling, and so on.

We can distinguish two liquidity spirals that emerge in this context and amplify the effects of initial shocks. The first is the loss spiral, which is depicted in the outer circle of Figure 3. The loss spiral is driven by the loss of net worth of traders and financial institutions during crises. The second liquidity spiral is the margin/haircut spiral, which is depicted in the inner circle in Figure 3. The margin spiral works primarily through increased volatility during crises. As volatility increases, margins and haircuts increase, which reduces the maximum leverage investors can take on. The resulting fire sales can lead to higher volatility, which exacerbates the initial shock and leads to a further tightening of margins. The two liquidity spirals affect a broad array of risky assets and can spill over across various investors, leading to contagion and the flight-to-safety phenomenon. Moreover, the two liquidity spirals are often at work at the same time and reinforce each other.

Net worth matters in these models because the issuance of equity is limited. For example, experts can issue only a certain amount of equity, since they are subject to a "skin in the game" constraint as in Holmström and Tirole (1997). In addition, investors may also face a constraint on debt issuance (or, equivalently, leverage). For secured lending, the leverage ratio is capped by the margins - often also expressed as haircuts or loan-to-value ratios. For unsecured lending, the total quantity of lending might be rationed since part of future cash flow is non-pledgeable as in Hart and Moore (1994). 


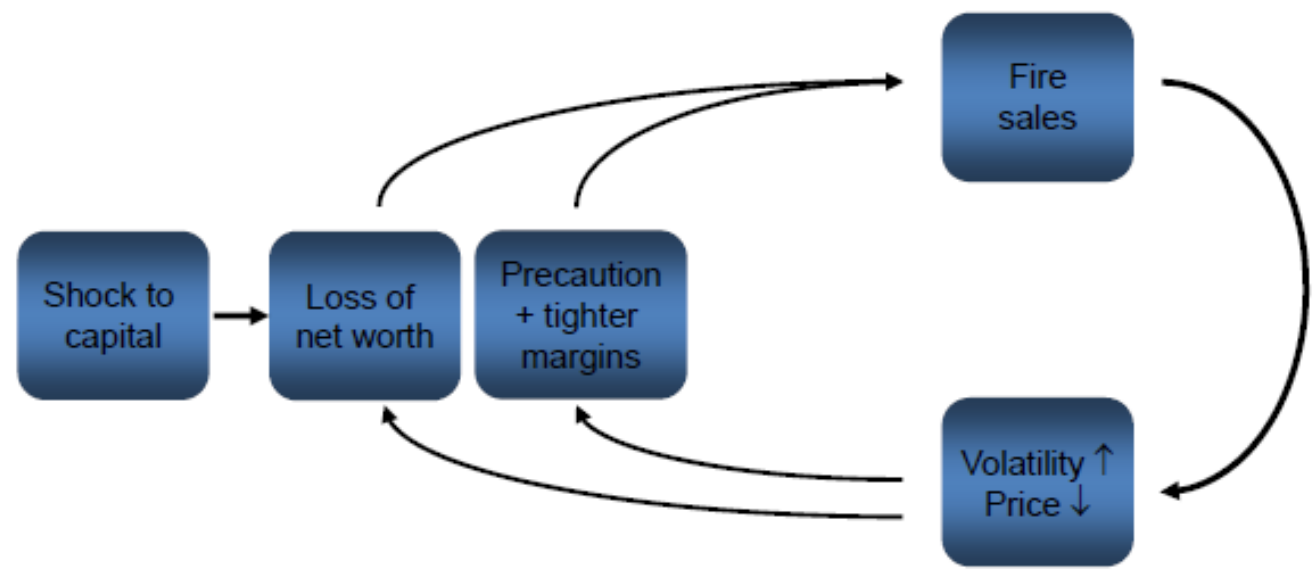

Figure 3: Liquidity spirals during financial crises. The figure illustrates the two components of liquidity spirals: the (i) loss spiral (outer circle) and (ii) the margin spiral (inner circle).

Alternatively, higher borrowing may be limited because raising the interest rate on loans may worsen the pool of loan applicants, leading to a "lemons" problem as in Stiglitz and Weiss (1981).

We now discuss both liquidity spirals in turn before focusing on the contagion and flight-to-safety aspects.

\subsubsection{Loss Spiral}

The loss spiral arises because a decline in asset values erodes the net worth of levered financial institutions much faster than their gross worth (total assets). For example, if a financial institution has a leverage ratio of 10 , a loss of $5 \%$ on its assets leads to a jump in the leverage ratio from 10 to 19. If this decline in asset value is permanent, a financial institution might want to sell some of these assets to return to its target leverage ratio. However, even when the decline in asset value is only temporary, financial institutions might be forced to reduce their exposure, even though they would still be at their target leverage after the temporary shock disappears. This is particularly the case when the financial institution's liquidity mismatch is high, i.e., when assets can only be sold with a large price impact (low market liquidity) and liabilities are short-term (low funding liquidity). Importantly, it is not just a financial institution's individual liquidity mismatch that determines the size of the loss spiral. Rather, it is determined 
by the liquidity mismatch and aggregate selling of all institutions.

The loss spiral arises in equilibrium because natural buyers for the asset (buyers with expertise) may be constrained at the time. This was pointed out in the seminal paper by Shleifer and Vishny (1992): First-best users, for example industry peers, are likely to be constrained at the same time that a firm is in distress (consider, for example, selling airlines in the airline industry). As a result, assets are sold to second-best users at firesale prices. In a similar vein, in Allen and Gale (1994), limited market participation restricts the amount of capital available to absorb asset sales that result when agents are hit by preference shocks in the spirit of Diamond and Dybvig (1983). In Gromb and Vayanos (2002), arbitrageurs are subject to margin constraints and may hold back because of binding margin constraints today. Acharya and Viswanathan (2011) provide a model in which both the need to sell assets and the limited ability to buy at an interim date arise from moral hazard concerns that lead to credit rationing.

In addition to outright binding constraints, also traders that are not currently constrained may prefer to sit out and keep dry powder for future buying opportunities. For example, in Shleifer and Vishny (1997), expert arbitrageurs are concerned about equity capital outflows after an adverse price move. In Gromb and Vayanos (2002), arbitrageurs that are subject to margin constraints may hold back even if the constraint is not binding today (i.e., in anticipation of binding constraints in the future). In Kondor (2009), arbitrageurs also face margin constraints. If an initial mispricing persists, it has to widen in equilibrium since arbitrageurs' losses accumulate. A similar mechanism is also at work in Diamond and Rajan (2011), who show that this may induce banks with limited liability to hold on to impaired illiquid assets, even though this exposes them to default risk. In all of these models, a reduction in arbitrageurs' net worth reduces their ability to step in, which leads to a (static) loss spiral. In addition, arbitrageurs may also become more risk averse as their net worth declines. For example, in Xiong (2001) expert arbitrageurs that can trade in a potentially mispriced asset have log utility, such that their absolute risk aversion decreases with net worth. The risk of the asset's cash flow process, on the other hand, stays constant as the level of cash flows drops. Arbitrageurs stabilize asset prices during normal times, but may exacerbate price movements when their net worth is impaired.

Interestingly, losses to net worth can lead to long-lasting effects. This has been explored particularly in the macroeconomics literature that focuses on amplification and persistence of effects that arise from losses to net worth. For example, Bernanke and Gertler (1989) and Carlstrom and Fuerst (1997) study persistence in a costly-state- 
verification framework à la Townsend (1979) and Gale and Hellwig (1985). In these models, investments are optimally financed via debt contracts: A debt contract minimizes the verification costs since they are incurred only in states where the entrepreneur defaults. In Bernanke and Gertler (1989), an adverse shock lowers the net worth of the leveraged entrepreneurs. The lower the entrepreneurs' net worth, the higher the probability of default, such that expected verification costs increase. This lowers overall economic activity, profits, and retained earnings. Most importantly, it can take several periods for entrepreneurs to accumulate sufficient retained earnings such that their net worth is high enough for economic output to reach its full potential. Losses to net worth thus cause persistent effects.

In addition to persistence, the macro literature has also pointed out that the dynamic amplification effect dwarfs the simple static (within period) amplification effect. In Bernanke, Gertler, and Gilchrist (1999) this arises because of technologically illiquidity of capital (via the introduction of non-linear costs in the adjustment of capital). As a consequence, the price of physical capital is procyclical, which amplifies the net worth effects. Kiyotaki and Moore (1997) identify a dynamic amplification mechanism in a setting in which entrepreneurs face a debt constraint and cannot issue any equity. More specifically, each productive entrepreneur's borrowing is limited by the collateral value of his physical capital in the next period. After an unanticipated productivity shock, leveraged entrepreneurs' net worth drops. Like in the models mentioned above, economic activity is depressed in future periods as well and it takes a long time to rebuild entrepreneurs' net worth. This period's temporary shock not only adversely impacts future periods, but the cutback of investment in the future also feeds back to the current period. Reduced future investment depresses future asset prices, but since this reduction is fully anticipated, it already depresses the current asset price, which again lowers current collateral values, current borrowing, and investment. The dynamic amplification mechanism in Kiyotaki and Moore (1997) quantitatively dominates the purely static loss spiral.

Brunnermeier and Sannikov (2010) derive a fully dynamic and stochastic model in which shocks occur with strictly positive probability. In addition to the dynamic amplification effects, an interesting endogenous volatility dynamic emerges. Expert investors only face an equity constraint and they limit their leverage for precautionary reasons: They want to preserve buying power should others have to fire-sell their assets in the future. The paper shows that the economy spends a lot of time close to the steady state, around which amplification is small. Occasionally, however, the economy 
ends up in a crisis state and it can take a long time for the economy to emerge from this crisis. The model also shows that a reduction in fundamental volatility can lead to higher overall volatility of the system - the volatility paradox. The reason is that when fundamental volatility falls, endogenous risk rises since expert investors take on higher leverage. Amplification effects also arise in the limited participation model of He and Krishnamurthy (2012), in which households can invest in the risky asset only through intermediaries. Given the agency problem between households and intermediaries, the net worth of the latter is the key state variable.

\subsubsection{Margin/Haircut or Leverage Spiral}

We now discuss the margin spiral. So far we have not explained why a drop in asset prices leads to higher margins, haircuts, and a more cautious attitude towards lending. If the drop in the asset price is temporary - for example, resulting from a lack of liquidity - investors with the necessary expertise should be facing good buying opportunities. Hence, one might think that lenders would be willing to lend more freely by lowering margins when prices drop for liquidity reasons. Even if the price shock is permanent, it is not immediately clear why, in percentage terms, the margin on the asset should increase after a price drop.

However, there are at least two reasons why one may expect margins to increase after a downward price move. First, as in unsecured lending, asymmetric information problems can become more severe after a large price drop. For one, financiers may become especially careful about accepting assets as collateral if they fear receiving a particularly bad selection of assets. They might, for example, be worried that structured investment vehicles have already sold off good, marketable assets, such that the assets left are less valuable "lemons." Relatedly, after a price drop, the collateral asset can become more informationally sensitive, leading to asymmetric information. While it may not be worthwhile to collect information about a debt security as long as default is extremely unlikely, after bad news default is more likely, and suddenly people with better information technology have an incentive to collect private information. This in turn creates asymmetric information and a lemons problem. Alternatively, when debt becomes more informationally sensitive, this increases the impact of pre-existing asymmetric information (see Gorton and Pennacchi (1990) and Dang, Gorton, and Holmström (2010)).

Second, unexpected price shocks might be a harbinger of higher future volatility. 
Because margins are set to protect financiers against adverse price movements in the collateral asset, margins (or, equivalently, haircuts) typically increase with volatility. Geanakoplos (2003) considers an example with "scary bad news" where bad news leads to higher fundamental volatility in the future. More generally, Geanakoplos (1997, 2003) studies endogenous collateral/margin constraints in a general equilibrium framework in which no payments in future periods/states can be credibly promised unless they are $100 \%$ collateralized with the value of durable assets.

In Brunnermeier and Pedersen (2009), the (dollar) margin $m_{t}$ has to be large enough to cover the position's $\pi$-value-at-risk (where $\pi$ is a non-negative number close to zero, e.g., 1\%):

$$
\pi=\operatorname{Pr}\left(-\Delta p_{t+1}^{j}>m_{t}^{j+} \mid \mathcal{F}_{t}\right)
$$

The margin/haircut is implicitly defined by equation (4) as the $\pi$-quantile of next period's value change $\Delta p_{t+1}^{j}$ of collateral asset $j$. Each risk-neutral expert has to finance $m_{t}^{j+} x_{t}^{j+}$ of the total value of his (long) position $p_{t}^{j} x_{t}^{j+}$ with his own equity capital. The same is true for short positions $m_{t}^{j-} x_{t}^{j-}$. Thus margins/haircuts determine the maximum leverage (and loan-to-value ratio).

As the estimated volatility of the potential price changes in the collateral asset, $\Delta p_{t+1}^{j}$, increases, so does the margin. In practice, these volatility estimates are often backward looking as institutions use past data to predict future volatility. Hence, a sharp price change increases volatility estimates. In Brunnermeier and Pedersen (2009) fundamental volatility is truly clustered. That is, a large shock today leads to an increase in future volatility that only slowly returns to its normal level $\underline{\sigma}^{j}$.

Most of the time, price movements in this model are governed by fundamental cash flow news. Occasionally, however, temporary selling (or buying) pressure arises that reverts only in the next period. Without credit constraints, risk-neutral experts would bridge the asynchronicity between buying and selling pressure, provide market liquidity, and thereby ensure that the price $p_{t}^{j}$ of asset $j$ follows its expected cash flow $v_{t}^{j}$. In other words, any temporary selling or buying pressure is simply offset by risk-neutral experts. When experts face credit constraints, in the sense that they have to raise financing from a group of financiers, their activity is limited and the price $p_{t}^{j}$ can deviate from $v_{t}^{j}$. The financiers, who set the margins at which they lend to the experts, attribute large price changes mostly to shifts in fundamentals, since they occur more frequently than the temporary liquidity shock that arises due to asynchronicity between buying and selling pressure. 
After a price shock, margins/haircuts widen, forcing experts to take smaller positions. Margins are thus destabilizing. The more sensitive margins are to a change in price level (which indirectly results from the persistence of fundamental volatility), the lower the experts' funding liquidity. In the extreme case, if margins were to jump to $100 \%$, margin funding dries up completely and experts cannot lever their positions at all. This is equivalent to not being able to roll over debt, because the firm becomes unable to use its assets as a basis for raising funds. Hence, margin sensitivity and short-term maturity of liabilities are two equivalent forms of funding illiquidity.

Low funding liquidity on the liability side of the balance sheet, combined with low market liquidity (price impact) on the asset side (high liquidity mismatch), leads to the liquidity spirals shown in Figure 3. When market liquidity is low, then selling the asset depresses the price, which in turn worsens funding liquidity, which leads to even more forced selling. Importantly, these two liquidity concepts do not exist in a vacuum; they are influenced by the financial soundness of other financial institutions. If other experts were able to buy the assets and stabilize the price, expert $i$ 's constraint would be relaxed and he could buy more assets as well (note that this is a form of strategic complementarity) ${ }^{13}$ In price theory terms, the experts' demand function for the asset is backward bending. As the price drops, margins increase and, rather than buying more assets, experts become more constrained and can only buy fewer assets 14

In addition, investors with buying capacity may be reluctant to purchase collateral assets because they anticipate that they may not be able to finance this purchase in the future and may have to sell the asset at a discount themselves. This dynamic arises when potential buyers have to finance their purchases using short-term debt and are thus exposed to rollover risk. Acharya, Gale, and Yorulmazer (2011) show that, in this situation, relatively small changes in the fundamental value of the collateral asset can lead to large changes in its debt capacity. This channel again highlights the important implications of liquidity mismatch during financial crises.

Shocks to agents' funding conditions can also cause liquidity spirals of deteriorating market liquidity, funding liquidity, and falling prices, with spillover effects across markets. Just like the risk of a traditional counterparty bank run by depositors leads to multiple equilibria in Diamond and Dybvig (1983), so does the risk of a collateral run

\footnotetext{
${ }^{13}$ In more extreme cases, other traders might even engage in "predatory trading," deliberately forcing others to liquidate their positions at fire-sale prices, as in Brunnermeier and Pedersen (2005).

${ }^{14}$ In Gennotte and Leland (1990), demand curves are backward bending since a portfolio insurance trading strategy prescribes agents to sell as the price falls.
} 
of increased margin requirements by financiers in Brunnermeier and Pedersen (2009). When other financiers demand high margins, this high margin becomes self-fulfilling. Collateral runs are the modern form of bank runs that occurred in the ABCP and repo market in 2007 and 2008.

Specifically, there exists one equilibrium in which experts can absorb the selling pressure and thereby stabilize the price. Hence, financiers predict low future price volatility and set low margins/haircuts. These low margins enable experts to absorb the selling pressure in the first place. In contrast, in the illiquidity equilibrium, experts do not absorb the selling pressure and the price drops. As a consequence, financiers think that future volatility will be high and, consequently, they charge a high margin. This in turn makes it impossible for experts to fully absorb the initial selling pressure.

One important implication of the analysis is that as experts' net worth falls, possibly due to low realization of $v$, the price eventually drops discontinuously from the perfect liquidity price with $p_{t}^{j}=v_{t}^{j}$ to the price level of the low liquidity equilibrium. This discontinuity feature is referred to as fragility of liquidity. Besides this discontinuity, price is also very sensitive to further declines in experts' net worth due to two liquidity spirals: The (static) loss spiral and the margin/haircut spiral both lead to de-leveraging. Adrian and Shin (2010) provide empirical evidence for these spirals for investment banks by showing that their leverage is procyclical. Gorton and Metrick (2011) document that such increases in margins occurred in parts of the (bilateral) repo market during the financial crisis of 2007-09. Krishnamurthy, Nagel, and Orlov (2011) and Copeland, Martin, and Walker (2010), on the other hand, show that margins in the tri-party repo market were relatively stable. However, commercial banks seem to have a countercyclical leverage, according to He, Khang, and Krishnamurthy (2010), potentially because they had access to the Fed's lending facilities.

Marking to market. The choice of accounting rules involves a trade-off between the loss spiral and the margin spiral. If all positions are marked to market, the loss spiral is more pronounced as holders of assets have to recognize losses immediately. On the other hand, allowing financial institutions to hide their losses through more flexible mark-to-model accounting rules does not necessarily stabilize markets. The reason is that, relative to marking to market, mark-to-model accounting rules may lead to more asymmetric information between borrowers and lenders and may thus exacerbate the margin spiral.

The loss spiral is more pronounced for stocks with low market liquidity, because sell- 
ing them at a time of financial distress will bring about a greater price drop than selling a more liquid asset would. For many structured finance products, market liquidity is so low that no reliable price exists because no trade takes place. As a consequence, owners have considerable discretion over the value at which a particular asset is marked. Selling some of these assets in a financial crisis would establish a low price and force the holder to mark down remaining holdings. Hence, investors are reluctant to do this - and instead prefer to sell assets with higher market liquidity first.

\subsubsection{Contagion and Flight to Safety}

Both losses to net worth and tightening margins can also lead to contagion. In a setting with multiple assets, risky asset prices might comove (even though their cash flows are independently distributed) since they are exposed to the same funding liquidity constraint. Losses can also generate contagion between assets when those assets are held by common investors. For example, in a multi-asset extension of Xiong (2001), Kyle and Xiong (2001) show that adverse wealth effects from losses lead to price declines across various asset classes.

In times when experts' net worth is depressed, the difference in market liquidity between high margin and low margin assets increases - a phenomenon that is often referred to as flight to quality. This in turn can lead to larger endogenous margins, exacerbating the price difference even further. At those times, assets with different (exogenous) margins might trade at vastly different prices even though their payoffs are very similar, resulting in a violation of the law of one price. Garleanu and Pedersen (2011) provide a theoretical model that underscores this point, while Mitchell and Pulvino (2012) provide empirical evidence from the 2008 financial crisis.

Vayanos (2004) studies a multi-asset general equilibrium model with stochastic volatility. Fund managers face transaction costs and are concerned about possible fund outflows. Vayanos shows that, during volatile times, liquidity premia increase, investors become more risk averse, assets become more negatively correlated with volatility, assets' pairwise correlations can increase, and illiquid assets' market betas increase.

Closely related is the flight to safety effect. Less informed financiers, who set margins, cut back their funding to leveraged expert investors and park their funds in nearly risk-free assets. The prices of risky assets with low market liquidity fall, while prices of flight-to-safety assets increase (as long as their supply is not perfectly elastic). A good example of this phenomenon is the U.S. Treasury market during the summer of 
2011, when political wrangling about lifting the U.S. debt ceiling led to a downgrading of U.S. Treasuries and an increase in CDS spreads on U.S. debt. At the same time, the yield on U.S. Treasuries actually decreased, as investors fled to the "safe haven" asset, U.S. Treasuries. Similarly, when Germany extended debt guarantees to the European Financial Stability Fund, its debt became more risky and CDS spreads increased. Yet, at the same time, large flight-to-safety capital flows from Spain and Italy into German government bonds significantly lowered the yield on German bonds. Interestingly, which asset obtains "flight-to-safety status" involves coordination. If most market participants think that people will flee to a particular asset in times of crisis, this asset enjoys higher market liquidity and hence is automatically safe as long as the cash flow risk is somewhat contained.

\subsection{Lenders' or Borrowers' Friction?}

In studying amplification mechanisms, we have up to now focused mostly on the balance sheets of the borrowers of funds and have assumed that lenders have deep pockets. For example, in Bernanke, Gertler, and Gilchrist (1999) and Kiyotaki and Moore (1997) it is the weakness of borrower balance sheets that causes amplification and persistence. However, another potential channel for amplification is on the lending side - in particular, the balance sheets of banks and other financial institution. When lenders have limited capital, they may restrict their lending as their own financial situation worsens, thus amplifying shocks. We can distinguish two main mechanisms through which this happens: (i) moral hazard in monitoring and (ii) precautionary hoarding.

Distinguishing whether frictions arise on the borrower's or the lender's side is important, because the location of the friction may have implications for which regulatory interventions are appropriate. When the friction is on the borrower's side, the appropriate policy reaction may be to recapitalize or subsidize borrowers. On the other hand, if the balance sheets of financial institutions are restricting lending, then it may be optimal to recapitalize those institutions, as opposed to strengthening borrowers. To distinguish between these alternative channels, it is thus useful to have models that incorporate both: frictions on the borrower and on the lender side (a "double-decker" model). One influential framework that combines these two channels is the Holmström and Tirole (1997) model, in which financial institutions matter because they perform valuable monitoring services but need to be incentivized to do so.

The idea that financial intermediaries add value by monitoring borrowers goes back 
to Diamond (1984). The main mechanism behind this insight is one of returns to scale in monitoring. If firms raise financing directly from $m$ investors, monitoring by each investor results in duplication of monitoring effort. Alternatively, the $m$ investors can hand their funds to a financial intermediary, who then lends to the firm. The advantage of this setup is that only the financial intermediary has to monitor. Investors enter debt contracts with the financial intermediary and impose a non-pecuniary punishment whenever the financial intermediary cannot repay. This non-pecuniary penalty ensures that the financial intermediary will in fact monitor the borrower. Because investment projects are independent, if the financial intermediary lends to a sufficient number of firms, the law of large numbers makes sure it can always repay investors, such that nonpecuniary costs are never incurred. More generally, financial intermediation dominates direct lending as long as the intermediary finances a large enough number of borrowers 15

While the Diamond (1984) model establishes an important monitoring role for financial intermediaries, the model is less specific about how intermediaries are incentivized to monitor. This is captured in reduced form in a non-pecuniary cost that creditors impose on the financial intermediary in the case of default. Holmström and Tirole (1997) provide a framework that models monitoring incentives by financial intermediaries in a more full-fledged manner. Their main insight is that intermediaries must have a sufficiently large stake in the ultimate borrower to have incentives to monitor. This, in turn, means that the balance sheet of an intermediary limits the number of firms that intermediary can finance. Moral hazard arises when the net worth of the intermediary's stake falls because the intermediary may then stop monitoring, forcing the market to fall back to direct lending without monitoring.

Like Diamond (1984), the Holmström and Tirole (1997) model features three classes of agents: firms, banks, and uninformed investors. The model features moral hazard at two levels. First, firms must exert effort such that their projects are positive NPV. If they do not exert effort, they receive a private benefit, but the project becomes negative NPV. Second, banks can monitor firms (reducing their private benefit from shirking), but will monitor only if it is in their own interest to do so. The time line of the model is as follows. At date 0, firms seek to finance an investment that exceeds their assets, $I>A$. Firms can write contracts with both uninformed investors and banks. At date 1, banks can monitor the firm. Monitoring is efficient, but banks have to be given

\footnotetext{
${ }^{15}$ As discussed by Hellwig (2000), the analysis changes when risk aversion is added. In particular, if borrowers are risk averse, financial intermediaries provide financing and insurance services, and it may be optimal to shift risk away from borrowers.
} 
incentives to do so. In particular, a bank's stake in the firm's investment must be large enough to make monitoring at cost $k$ individually rational for the bank. At date 2 , all cash flows are realized.

Firms that have sufficient assets, $A \geq \bar{A}$, can finance their project directly from uninformed investors. Intuitively speaking, these firms have enough skin in the game to exert effort such that no monitoring by banks is needed. Since monitoring is costly, it is more efficient for those firms to raise all financing directly from the uninformed investors. Firms with weaker balance sheets, $\underline{A} \leq A<\bar{A}$, can raise funding only if they are monitored by banks. In order to do so, they raise part of their funding from banks (such that the bank just finds it individually rational to monitor) and raise the remainder in the form of cheaper funding from uninformed investors. Importantly, because banks have to hold a minimum stake in each firm they finance, the number of firms that can receive monitored bank financing depends on the amount of capital in the banking system, $K_{m}$.

In the Holmström and Tirole (1997) model, both lender and borrower balance sheets matter. Stronger borrower balance sheets (a first-order stochastic dominance shift in the distribution of borrower assets $A$ ) lead to an increase in output, illustrating the borrower balance-sheet channel. A weakening of bank balance sheets leads to a contraction in financing, illustrating how the lending channel can lead to a credit crunch. One implication of this finding is that financial crises that significantly impair the balance sheets of financial institutions can have significant negative repercussions on output and real activity.

Rampini and Viswanathan (2011) provide a dynamic model that incorporates the balance sheets of both financial institutions and the corporate sector. In contrast to Holmström and Tirole (1997), financial intermediaries are not monitoring specialists but collateralization specialists: They are better able to collateralize claims than the household sector. However, financial intermediaries are themselves constrained because they have to raise their funding from the household sector, which is less good at lending against collateral. This means that both the balance sheets of financial intermediaries and the balance sheets of the corporate sector are state variables that affect the dynamics of the economy. One important implication of their model is that, after a shock to net worth, financial intermediaries accumulate capital more slowly than the corporate sector. The reason is that for poorly capitalized firms, the marginal product of capital is high relative to the spread that financial intermediaries can earn, such that the corporate sector accumulates wealth faster. Because of this, a credit crunch (a reduction 
in the net worth of financial intermediaries) leads to a persistent reduction in output, and the economy recovers only slowly.

An alternative channel through which lender balance sheets can affect output is precautionary hoarding. Such precautionary hoarding arises if lenders are afraid that they might suffer from interim shocks, such that they will need funds for their own projects or trading strategies. The anticipation of those future shocks may then lead to a cutback in lending today, comparable to precautionary savings in the classic consumption-savings model. Precautionary hoarding is therefore more likely to arise when the likelihood of interim shocks increases, and when outside funds are expected to be difficult to obtain in the states where the shocks hit. Gale and Yorulmazer (2011) provide a model of such precautionary liquidity hoarding. Their model also points to a speculative motive for liquidity hoarding, because banks may choose to hold cash in order to exploit potential fire-sale buying opportunities in the future. From a policy perspective, an implication of their model is that banks hoard more liquidity than a social planner would, generating a role for intervention by central banks to "unfreeze" lending markets.

The troubles in the interbank lending market in 2007-08 are a textbook example of precautionary hoarding by individual banks. As it became apparent that conduits, structured investment vehicles, and other off-balance-sheet vehicles would likely draw on credit lines extended by their sponsored bank, each bank's uncertainty about its own funding needs skyrocketed. At the same time, it became more uncertain whether banks could tap into the interbank market after a potential interim shock, since it was not known to what extent other banks faced similar problems. This led to sharp spikes in the interbank market interest rate, LIBOR, relative to Treasuries.

\subsection{Network Externalities}

All our settings so far have assumed a distinct lending sector that provides credit to a distinct borrowing sector. In reality, however, most financial institutions are lenders and borrowers at the same time: The modern financial architecture consists of an interwoven network of financial obligations. This network structure may play an important part in propagating financial shocks during financial crises.

The literature on financial networks is still in its infancy. A number of papers start

with a given financial network and highlight spillovers and amplification mechanisms within this network. In some papers these spillovers occur via direct "domino effects," while other papers embed amplification via prices or bank runs into a network structure. 
Another emerging strand of this literature investigates network formation. A central question here is whether an endogenous financial network will be efficient, or whether it may become too complicated or excessively interconnected. Finally, network models are central to the literature on payment systems and settlement risk.

The most direct way for losses to propagate through a financial network is via direct linkages between the balance sheets of financial institutions, or firms more generally. The default of one financial institution on its obligations leads to losses on the balance sheets of other financial institutions, which may lead to further defaults, and so on. Eisenberg and Noe (2001) provide a model of such direct network dependence. Essentially, starting with an initial default somewhere in the network, one has to check whether other institutions in the system are able to make their payments given the initial default. If this is not the case, at least one more institution defaults and one then checks whether, given these additional losses, other institutions can make their payments. This process continues until no further defaults are caused. Because in this framework an initial default can lead to further defaults only via direct balance-sheet linkages, it is sometimes referred to as the domino model of contagion.

A number of studies have investigated the domino model of contagion using simulation studies (e.g., Upper and Worms (2004), Degryse and Nguyen (2007)). The conclusion from these simulation studies, however, is that contagion through direct domino linkages is usually not sufficiently strong to generate large crises. In this framework, only very large initial shocks would lead to significant contagion. Perhaps this should not be surprising. First of all, the direct domino model of contagion takes a very static view of the financial system, in the sense that financial institutions are completely passive and stand by as the initial shock feeds through the system. In practice, endogenous responses by financial institutions to the initial shock may amplify its impact. Second, the model of direct domino effects abstracts away from propagation through price effects. Specifically, the initial default leads to losses only through direct losses on obligations. However, if the initial default also leads to decreasing asset prices, this provides an additional channel through which contagion can spread through the system (for example, because financial constraints become tighter for all firms in the network). Cifuentes, Ferrucci, and Shin (2005) add asset prices to a domino model of contagion. In addition to direct bilateral exposures, contagion now also spreads through the effects of decreasing asset prices on banks' balance sheets. The two channels of contagion reinforce each other, which allows for more substantial contagion effects.

Another mechanism that can amplify contagion within a network is the presence 
of bank runs. As is well known from Bhattacharya and Gale (1987), banks may form networks to pool liquidity risk via the interbank market. However, such an arrangement can also be a breeding ground for financial contagion, as pointed out by Allen and Gale (2000b). Their model is a variant of Diamond and Dybvig (1983), in which banks are connected in a network. The number of early consumers is random for each individual bank, but the aggregate demand for liquidity at the intermediate date is constant. Banks can thus insure each other via interbank deposits: A bank with a large number of early consumers can obtain liquidity from a bank with a small number of early consumers.

As long as the overall liquidity demand is as expected, this type of insurance works well, as in Bhattacharya and Gale (1987). However, Allen and Gale (2000b) show that in the presence of a small unanticipated excess demand for liquidity, interconnections via interbank deposits can lead to contagion. When the amount of liquidity in the system is insufficient, banks have to liquidate some of the long-term investment. If the amount that a bank has to liquidate is sufficiently large, a bank run is triggered and the bank liquidated. But this means that other banks with deposits in the defaulting bank suffer a loss, which may mean that they cannot serve their liquidity needs and may suffer a bank run as well. The main insight in Allen and Gale (2000b) is that this type of contagion depends on the network structure. For example, if all banks are connected and hold interbank deposits with each other, an initial shock is spread evenly among all other banks, which makes contagion less likely. When not all banks are connected, on the other hand, the losses from an initial shock are concentrated in a smaller number of other banks, which makes contagion more likely.

In Allen and Gale (2000b), the liquidity shock that leads to contagion is unanticipated (or occurs with very small probability), such that banks do not adjust their liquidity buffers in response to the possible crisis. Moreover, because the crisis occurs with arbitrarily small probability, it is socially optimal in their model not to insure against the crisis. Zawadowski (2011) develops a related model in which banks that are connected in a network know that they face future counterparty risk with positive probability and can choose to insure against this risk. Zawadowski shows that because of a network externality, it is possible that banks do not insure against future counterparty losses even though this would be socially desirable.

Network risk has also received considerable attention in the literature on payment systems. For example, Bech and Soramäki (2001) point out the possibility of gridlock in the payment system. Consider a situation in which bank A owes 1 dollar to bank 
B, bank B owes 1 dollar to bank $\mathrm{C}$, and bank $\mathrm{C}$ owes 1 dollar to bank A. In a gross settlement system without netting, gridlock can ensue because each party can only pay its obligation if it receives the dollar it is owed. If obligations were first netted out, this situation would not arise ${ }^{16}$ Such gridlock risk may arise in particular when individual banks become more cautious about sending payments, which in turn may make other banks take a more cautious stance as well. Afonso and Shin (2011) study this dynamic in a model calibrated to one of the major U.S. payment systems, Fedwire. In their framework, individually rational cautious behavior by banks is mutually reinforcing. This can lead to illiquidity spirals in the payment system.

Rotemberg (2011) extends this type of analysis to investigate how much liquidity has to be in the system in order to avoid such gridlock. This depends on the financial network. In particular, when the system is more interconnected, such that each firm has more net creditors, more liquidity may be needed. The reason is that when firms have a choice regarding which obligation to pay, they may send a dollar of liquidity to nodes where it cannot be reused (i.e., continue to circle through the network).

Rotemberg's analysis also points to the public-good nature of netting, novation, and trade compression within a network $[17$ In particular, if simplifying the financial network via netting, novation, or trade compression benefits not only the parties that agree to net their trades, but also the remainder of the network, then the public-good nature of these netting transactions may lead to a financial network that is more interconnected than would be optimal.

Another approach to network formation is given in Allen, Babus, and Carletti (2012), who show that the extent of information contagion in financial systems can depend on the network structure. In this model, banks choose the number of connections they make to other banks in order to diversify their portfolio, but they do not choose the overall network structure. For example, if there are six banks and each bank links to two other banks, this can result in either two circles of three banks (a clustered structure), or one large circle of six banks (an unclustered structure). When banks are financed by short-term debt and there is interim information on bank default

\footnotetext{
${ }^{16}$ Freixas and Parigi (1998) provide a model to compare gross and net payment systems. They show that the central trade-off is that gross payment systems make intensive use of liquidity, while net payment systems economize on liquidity but expose the system to contagion.

${ }^{17} \mathrm{~A}$ novation occurs when one side of a contract assigns its obligation to another party. This allows a party with two offsetting derivatives to step out of the picture, leaving only a contract between its two original counterparties. In a compression trade, partially offsetting contracts are compressed and replaced by a new contract. This is, for example, a common procedure in the CDS market.
} 
probabilities, information contagion is more likely to arise under the clustered network structure.

Why may a simpler financial network be preferable to a more interconnected system? One reason is network risk. Network risk is best illustrated by a simple example. Consider a hedge fund that has an interest rate swap agreement with investment bank A - that is, both parties have agreed to swap the difference between a floating interest rate and a fixed interest rate. Now suppose that the hedge fund offsets its obligation through another swap with a different investment bank. In the absence of counterparty credit risk, the two swap agreements can be viewed as a single contract between investment bank A and investment bank B; the hedge fund could simply step out of the contract. However, this is not the case in the presence of counterparty risk. In particular, it would be unwise for investment bank A to accept replacing the original contract with a contract with investment bank B if it fears that investment bank B might default on its commitment.

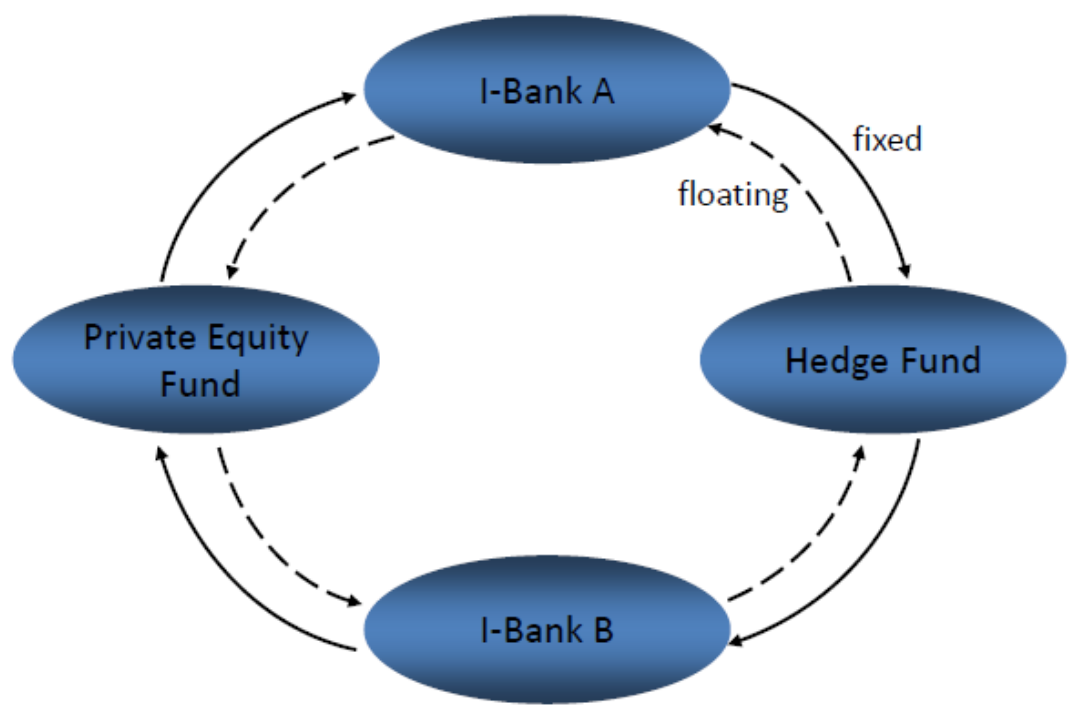

Figure 4: A network of interest rate swap agreements.

We can extend this example to see how an increase in perceived counterparty credit risk might be self-fulfilling and create additional funding needs. Suppose that investment bank B had an offsetting swap agreement with a private equity fund, which in turn offsets its exposure with investment bank A. In this hypothetical example, illustrated in Figure 4, all parties are fully hedged and, hence, multilateral netting could eliminate all 
exposures. However, because all parties are aware only of their own contractual agreements, they may not know the full situation and therefore become concerned about counterparty credit risk even though there is none. If the investment banks refuse to let the hedge fund and private equity fund net out their offsetting positions, both funds have to either put up additional liquidity, or insure each other against counterparty credit risk by buying credit default swaps. Anecdotally, this happened in the week after Lehman's bankruptcy in September 2008. All major investment banks were worried that their counterparties might default, such that they all bought credit default swap protection against each other. As a result of deteriorated credit conditions and the resulting buying pressure in the CDS market, the already high prices of credit default swaps written on the major investment banks almost doubled.

Network and counterparty credit risk problems are more easily overcome if a clearinghouse or another central authority or regulator knows who owes what to whom, thus allowing multilateral netting to take place. One way to guarantee efficient netting of obligations is by introducing a central clearing counterparty (CCP) for all trades. Duffie and Zhu (2011) show that whether a CCP improves netting efficiency depends on a trade-off between multilateral netting of one type of contract (for example, CDSs) among all counterparties, which is possible when a CCP has been introduced, and bilateral netting among many types of contracts (e.g., CDSs, currency swaps, interest rate swaps). For a CCP to increase netting efficiency, the multilateral netting gains created through the CCP must outweigh the losses in bilateral netting efficiency for the remaining OTC contracts. Another important issue when considering a CCP is the potential failure of the CCP itself. Specifically, while the presence of a CCP may reduce counterparty risk among traders in the market, a potential failure of the CCP itself would be a major systemic event. A CCP arrangement thus requires making sure that the clearing house is well capitalized.

\subsection{Feedback Effects between Financial Sector Risk and Sovereign Risk}

So far we have focused primarily on propagation and amplification mechanisms within the financial sector and from the financial sector to the real economy. In this section, we briefly discuss another important feedback effect that arises when sovereign debt becomes risky.

Financial institutions are usually encouraged (or even required) to hold a cer- 
tain amount of safe and liquid assets. Typically, sovereign debt issued by developed economies is considered to be such an asset. The rationale behind this reasoning is that a sovereign can always print money to service its debt, which makes debt denominated in domestic currency safe, at least in nominal terms. This (perceived) safety makes sovereign debt an attractive instrument for risk and liquidity management purposes by financial institutions. For example, many repo transactions rely on sovereign debt as collateral and the margins on sovereign debt are typically lower than those for other asset classes. Because of its perceived safety, sovereign debt of developed countries is assigned zero risk under the Basel bank regulation framework.18

However, even the debt of developed countries can become risky, as exemplified by the recent sovereign debt crisis in Europe.19 If financial institutions rely on sovereign debt for risk and liquidity management purposes, this introduces an interdependence of sovereign and financial sector risk, which is illustrated in Figure 5. This interdependence works through two main channels. First, an increase in the riskiness of government debt impairs financial institutions that have large exposures to sovereign risk. This increases the probability that the sovereign has to bail out the banking sector, which further compromises the fiscal position of the sovereign. This increases yields on sovereign debt and hence makes refinancing for the sovereign more challenging. Second, banks that suffer losses on their holdings of sovereign debt may reduce their lending to the real economy. The resulting decrease in credit slows down economic growth and thus reduces the sovereign's tax revenue, which again increases the riskiness of sovereign debt. In the context of the European debt crisis, this feedback mechanism has been referred to as the "diabolic loop" between sovereign risk and banking risk (Brunnermeier, Garicano, Lane, Pagano, Reis, Santos, Thesmar, van Nieuwerburgh, and Vayanos (2011)).

These feedback effects can be triggered either by an initial deterioration of the fiscal position of the sovereign (for example, due to unsustainable spending) or by losses in the banking sector (for example, when financial institutions are exposed to a crash in real estate prices). Empirically, Reinhart and Rogoff (2011) document three stylized facts that underscore these links between public debt and the financial sector. First, banking crises often follow increases in external debt. Second, banking crises in turn often precede or accompany sovereign debt crises. Third, public borrowing often increases prior to external sovereign debt crises, for example because the government assumes

\footnotetext{
${ }^{18}$ For example, under Basel II the risk weight on sovereign debt rated AA- and higher is is zero. Basel III is similar to Basel II in this respect.

${ }^{19}$ Reinhart and Rogoff (2009) provide an extensive survey of sovereign default over the centuries.
} 


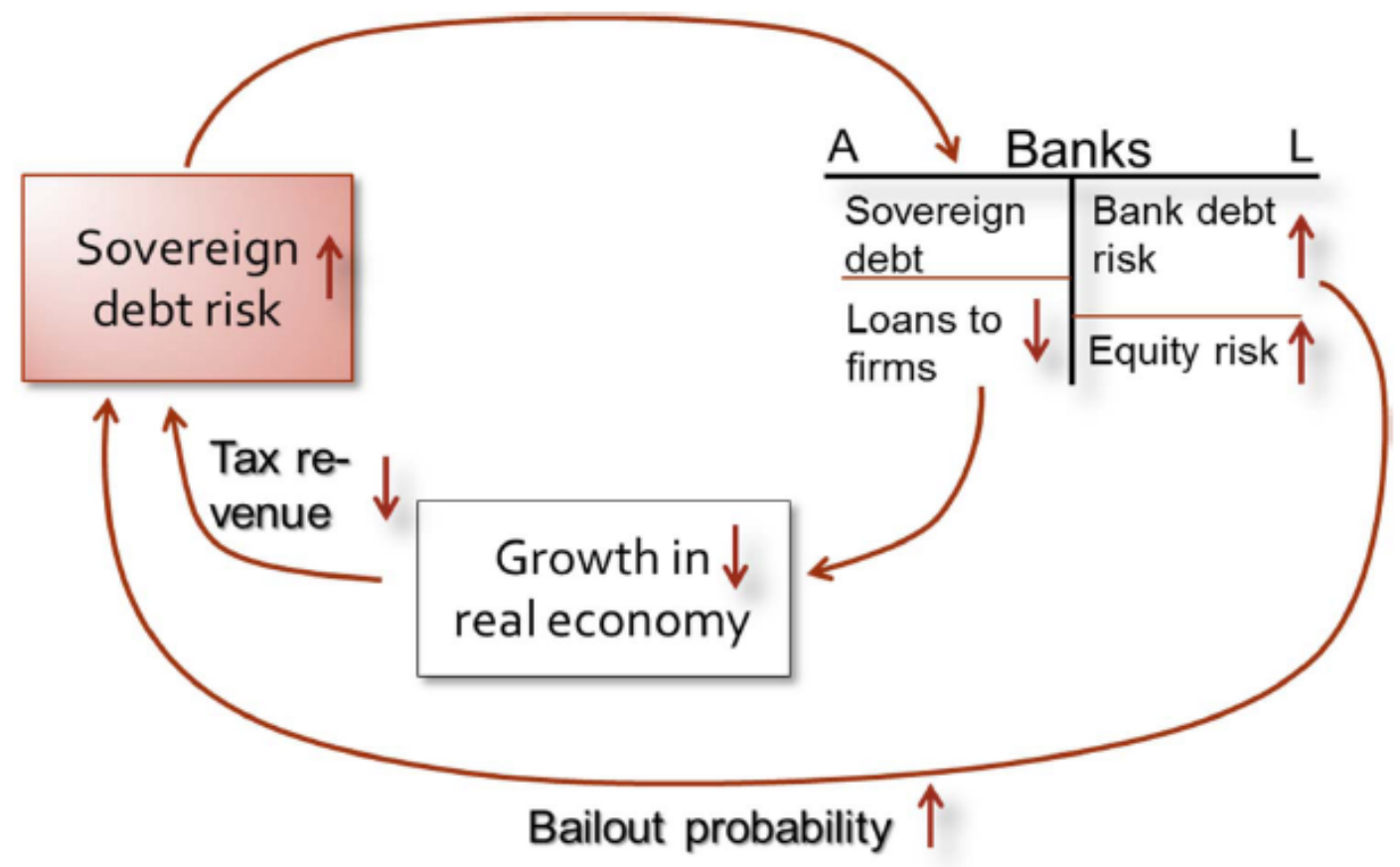

Figure 5: Feedback effects between sovereign and financial sector risk ("diabolic loop").

private debt as part of bailouts. Barth, Prabhavivadhana, and Yun (2012) document that these interdependencies are stronger in countries where the ratio of bank assets to GDP is relatively high.

A number of recent papers study these feedback effects between sovereign risk and financial sector risk ${ }^{20}$ Bolton and Jeanne (2011) develop a model of two financially integrated countries. The financial sectors in each country hold sovereign bonds, because safe bonds are required as collateral in the market for interbank loans. There is a possibility that one of the two countries defaults, such that for diversification purposes banks in each country hold debt issued by both sovereigns. While this generates ex-ante diversification benefits, it also generates contagion ex post: A default by one country is automatically transmitted to the other country via the integrated financial sectors. Another finding of the paper is that financial integration without fiscal integration (meaning that each country issues bonds individually) results in an inefficiently low

\footnotetext{
${ }^{20} \mathrm{An}$ earlier literature has stressed the connection between banking crises and currency crises. This link is documented in Kaminsky and Reinhart (1999), who coined the term "twin crises." See also Reinhart and Rogoff (2009).
} 
supply of safe government bonds and an excessively high amount of risky government debt. The safe country acts as a monopolist and restricts the supply of the safe-haven asset. The risky country, on the other hand, issues too much risky debt because it does not internalize the default costs it imposes on the other country.

Gennaioli, Martin, and Rossi (2011) also provide a model of the interaction between sovereign default, but in a one-country setting. Their key insight is that, when the domestic banking sector holds a large amount of sovereign debt, it is more costly for the country to default, as the default impairs the financial sector and leads to a reduction in private credit. This generates a complementarity between public borrowing and private credit markets. Countries with developed financial institutions that hold sovereign debt have more incentive to repay their debt since default would disrupt economic growth 21 From an ex-ante perspective, large exposure of the domestic financial sector to sovereign debt may thus have a benefit by incentivizing the sovereign to repay. The flip side of this argument, of course, is that ex post sovereign default in countries with highly developed financial sectors becomes particularly painful.

\section{$5 \quad$ Measuring Systemic Risk}

Systemic risk has two important elements: It builds up in the background during the run-up phase of imbalances or bubbles and materializes only when the crisis erupts. These two distinctive phases that shaped our survey so far also provide useful guidance on how to measure systemic risk.

\subsection{Systemic Risk Measures}

Measuring systemic risk is, to some extent, related to measuring firm risk. This makes risk measures at the firm level a natural starting point to think about systemic risk. Over the last two decades, a large literature has explored such firm-level risk measures.

The purpose of risk measures is to reduce a vast amount of data to a meaningful single statistic that summarizes risk. For example, expected utility or the certainty equivalent can be viewed as risk measures. Risk measures have become particularly important since the implementation of Basel II bank regulations, which rely heavily on

\footnotetext{
${ }^{21}$ This links their paper to one of the classic questions in the literature on sovereign debt: Why do countries repay? We do not survey this literature here. Good starting points are Obstfeld and Rogoff (1996) and Sturzenegger and Zettelmeyer (2006).
} 
the use of such risk measures.

The most common measure of risk used by financial institutions - the value at risk (VaR) - focuses on the risk of an individual institution in isolation. The $q$-VaR is the maximum dollar loss within the $q$-confidence interval; see Kupiec (2002) and Jorion (2006) for overviews. Formally, let $X^{i}$ be firm $i$ 's profit distributed with a strictly positive density; then the $V a R_{q}^{i}$ is implicitly defined as the quantile $q$, such that

$$
\operatorname{Pr}\left(-X^{i} \geq V a R_{q}^{i}\right)=q
$$

If $X$ does not have a positive density, the $q$ - $V a R$ is usually defined as

$$
V a R_{q}^{i}=\inf \left\{m \in \mathbb{R}: \operatorname{Pr}\left[X^{i}+m<0\right]\right\} \leq q
$$

The $q$ - VaR can be interpreted as the minimal capital cushion that has to be added to $X$ to keep the probability of a default below $q$.

While VaR is immensely popular, it has some well-known shortcomings. As pointed out by Artzner, Delbaen, Eber, and Heath (1999), VaR is not a coherent risk measure, in that it does not satisfy certain desirable criteria (or axioms). In particular, VaR is not convex in $X$ and can therefore fail to detect concentration of risks. The VaR also does not distinguish between different outcomes within the $q$-tail ${ }^{22}$

Other risk measures explicitly take into account the loss distribution in the $q$-tail. One such risk measure is the expected shortfall measure, which is defined as the expected loss conditional on being in the $q$-tail:

$$
E\left[-X^{i} \mid-X^{i} \geq V a R_{q}^{i}\right]
$$

The expected shortfall measure has better formal properties than VaR. For continuous distributions it agrees with average value at risk (AVaR) in the tail, which is a coherent risk measure (see, for example, Föllmer and Schied (2011)). Of course, one downside of the expected shortfall measure is that loss distributions within, say, the $1 \%$ tail are extremely hard to estimate, such that one usually has to make parametric assumptions on the tail distribution. From a practical point of view, it is thus not clear that the expected shortfall measure dominates the VaR.

\footnotetext{
${ }^{22} \mathrm{~A}$ popular example to illustrate the shortcomings of VaR is to contrast a portfolio of 100 bonds with independent default probabilities of $0.9 \%$, to the analogous portfolio with perfectly correlated defaults. The $1 \%$-VaR of the diversified portfolio is larger than the $1 \%$-VaR of the undiversified portfolio.
} 
While measuring systemic risk is related to measuring risk at the firm level, risk measures for individual financial institutions are typically not good systemic risk measures. The reason is that the sum of individual risk measures usually does not capture the systemic risk, i.e., the risk that the stability of the financial system is in danger as a whole. In addition, institutions that are individually equally risky (e.g., they have the same VaR) are not equally risky to the system. To see this, consider two institutions that are individually equally risky, but the first institution causes large adverse spillover effects when in financial distress, while the second institution does not.

Ideally, one would like to have (i) a systemic risk measure for the whole economy and (ii) a logically consistent way to allocate this systemic risk across various financial institutions according to certain axioms. For example, the overall systemic risk could reflect the risk premium society should charge for insuring the financial sector for bailout payments in crisis times. The allocation of this overall systemic risk to each individual financial institution should reflect each institution's total risk contribution to overall systemic risk. From an abstract perspective, systemic risk measures are thus related to firm-level risk measures that attempt to capture the total and marginal risk contributions of, say, a number of trading desks.

The literature distinguishes between several different risk allocation rules: The proportional allocation proposed by Urban, Dittrich, Klüppelberg, and Stolting (2003) assigns a fraction of total systemic risk to each institution, where each institution's fraction is given by institution $i$ 's individual risk measures divided by the sum of all institutions' individual risk measures. The with-and-without allocation, proposed by Merton and Perold (1993) and Matten (1996), calculates institution $i$ 's contribution to systemic risk as the difference in total systemic risk including institution $i$ and excluding institution $i$. The marginal version of this rule is referred to as the Euler or gradient allocation (see, for example, Patrik, Bernegger, and Rüegg (1999) and Tasche (1999)). Tsanakas (2009) and Tarashev, Borio, and Tsatsaronis (2009) suggest calculating a Shapley value as an allocation rule. ${ }^{23}$

Ideally, the allocation should be such that (i) the sum of all risk contributions equals the total systemic risk and (ii) each risk contribution incentivizes financial institutions to (marginally) take on the appropriate amount of systemic risk. However, capturing both total and marginal risk contributions in one measure is a challenging task, because the

\footnotetext{
${ }^{23}$ The Shapley value is a concept from cooperative game theory. The intuition behind the Shapley value is that it captures the average marginal contribution of a player to different coalitions that can be formed.
} 
relationship between the two may be non-linear (Brunnermeier and Cheridito (2011)). In fact, the marginal contribution of one institution may depend on the risks taken by other institutions.

Economically, a systemic risk measure should identify "individually" systemically important financial institutions (SIFIs) that are so interconnected and large that they can cause negative risk spillover effects on others. In addition, it should also identify institutions that are "systemic as part of a herd" (see Brunnermeier, Crocket, Goodhart, Persaud, and Shin (2009)). This second point is important because a group of 100 institutions that act in a correlated fashion can be as dangerous to the system as one large entity. This also means that splitting a SIFI into 100 smaller institutions does not stabilize the system as long as these 100 smaller "clones" continue to act in a perfectly correlated fashion. Hence, a good systemic risk measure should satisfy the "clone property," such that it also captures systemic risk emanating from smaller institutions that act in a correlated fashion.

\subsection{Data Collection and Macro Modeling}

Without appropriate data, even the clearest concept of systemic risk is only of limited use. This raises the question of which data one should collect to ensure financial stability. In response to the financial crisis of 2007-09, the U.S. Congress created the Office of Financial Research (OFR), which has been put in charge of collecting the data required to measure systemic risk and ensure financial stability.

In measuring systemic risk, the distinction between the run-up phase, during which imbalances and systemic risk build up in the background, and the crisis phase, in which systemic risk materializes and is propagated through the system, is again useful. In particular, the data requirements for these two phases are different.

Detecting imbalances that build up during the run-up phase requires low-frequency price and quantity data. Daily data would probably provide only very limited additional insights. Since the exact triggers of financial crises vary from crisis to crisis and are difficult to identify exactly, it is sensible to focus data collection on capturing vulnerabilities of the financial system. Certain environments might lead to more vulnerability and larger tail risks because they are conducive to large amplification effects. For example, the bursting of a credit bubble (like the stock market bubble in 1929 or the housing bubble in 2007) is usually more harmful to the economy than the bursting of a bubble that is not financed by credit (like the internet bubble of the late 1990s). To 
capture such vulnerabilities and tail risks in the financial system, data on both prices and quantities should be collected. Price data may include, for example, price ratios such as the price-dividend ratio for stocks or the price-rent ratio for real estate. Quantity data may include, among other things, current account imbalances and money and credit aggregates.

When systemic risk materializes in a crisis, spillover and amplification effects determine the overall damage to the economy. As pointed out in Section 4 , these often depend on the endogenous reaction of market participants, who are typically driven by funding considerations: A trader with deep pockets will react very differently to an extreme adverse shock compared to someone who funded his position on margins or with short-term debt. The "risk topography" approach proposed in Brunnermeier, Gorton, and Krishnamurthy (2012) attempts to take into account these endogenous responses. In this framework, the liquidity mismatch measure (Brunnermeier, Gorton, and Krishnamurthy (2013)) is the key response indicator.

Systemic risk cannot be detected by measuring only cash instruments. While prior to the introduction of derivative markets, flows in assets were a good proxy for risk exposures, through the introduction of derivatives, risk exposures have become divorced from the flows. It is therefore paramount to collect information on risk exposures directly, as opposed to measuring only flows in risky assets. More specifically, Brunnermeier, Gorton, and Krishnamurthy (2012) propose a two-step approach to collecting data and measuring systemic risk. First, all financial institutions report their risk exposures to a number of risk factors. For example, each institution reports its (partial equilibrium) change of net worth and change in the liquidity mismatch index in response to a price drop of, say, $5 \%, 10 \%$, or $15 \%$ in mortgage-backed securities. After these responses have been collected, the second step is conducted by financial regulators. Reported changes in liquidity mismatch allow regulators to predict the market participants' endogenous responses to an initial shock. For example, it allows them to predict whether financial institutions need to fire-sell some of their assets. Importantly, the regulators look at individual responses in the context of a general equilibrium framework that takes into account collective reactions by market participants. The regulators may then possibly conclude that a $15 \%$ price drop is much more likely than a $5 \%$ or $10 \%$ price decline, given that most market participants' endogenous response to a shock is to sell assets. Conceptually, this method allows regulators to identify mutually inconsistent plans by market participants: If the risk management strategy of many market participants is to sell assets in response to a price decline, then prices will drop by a large margin 
in response to a shock. The method also helps to reveal pockets of illiquidity and the potential for "crowded trades." If the regulator observes that certain asset classes are likely to be sold in response to shocks, these asset classes are likely to be illiquid during crises. While in the above example the risk factor we considered was exposure to price fluctuations in a certain asset class (mortgage-backed securities, in this specific example), risk factors should also include worsening of funding conditions, such as increases in haircuts, and potential defaults by counterparties.

Duffie (2012) proposes a network-based 10-by-10-by-10 approach that also relies on financial institutions reporting their exposures to risk factors. In this proposal, each of the, say, 10 largest financial institutions would report the gains and losses for 10 different scenarios, relative to the 10 counterparties that are most affected in a given scenario. These scenarios could include the default of a counterparty, changes in credit spreads, changes in the yield curve, etc. The data collection effort asks financial institutions to identify their counterparties themselves. The number 10 is simply a placeholder and can be easily adjusted. While the 10-by-10-by-10 approach does not emphasize endogenous responses by market participants, it is appealing because it captures direct spillover effects among the largest financial institutions in an easily implementable fashion.

To measure spillover effects and evaluate policy measures during times of crisis, more granular data, or even high-frequency position data, may be useful. Importantly, these data should be comprehensive in the sense that they should capture the whole portfolio of financial institutions (and not only parts of it). For example, simply knowing a firm's CDS exposure is only of limited use if one does not have access to the firm's positions in the underlying bond.

A detailed discussion of which exact data may be useful and which asset classes the regulator should monitor goes beyond the scope of this chapter. For further reading, the collection of articles in Brunnermeier and Krishnamurthy (2013) provides an in-depth analysis of data collection efforts across different markets. Rather than going into those specificities, in what follows we merely discuss some of the conceptual challenges in estimating systemic risk measures.

\subsection{Challenges in Estimating Systemic Risk Measures}

Even a systemic risk measure that satisfies the desired properties is not very useful if it cannot be estimated empirically. In particular, for a risk measure to be useful, the inputs into the risk measure must be measurable in a timely fashion. However, 
such timely measurability is challenging for several reasons. First, tail events are by definition rare, resulting in scarcity of data. In addition to this lack of data, many variables cannot be observed reliably. For example, simple leverage measures may not capture leverage that is embedded in certain assets held by financial institutions. Moreover, because systemic risk usually builds up in the background during the lowvolatility environment of the run-up phase, regulations based on risk measures that rely mostly on contemporaneous volatility are not useful. They may even exacerbate the credit cycle. Hence, the volatility paradox rules out using contemporaneous risk measures and calls for slow-moving measures that predict the vulnerability of the system to future adverse shocks.

To avoid using contemporaneous data or inputs that are hard to measure, Adrian and Brunnermeier (2008) propose to first project the preferred systemic risk measures onto more reliably measurable lagged characteristics, such as liquidity mismatch, size, and leverage. Confidential supervisory data about financial structure that track features such as counterparty exposures, contingent credit lines, and other contractual linkages among institutions may also be useful. These regressions, in turn, give an indication as to which observable variables can help predict future crashes and thus help measure the current vulnerability of the financial system. Of course, this approach is subject to a Lucas critique. If certain characteristics are used for financial regulation, then individual institutions will try to manipulate their reported characteristics, and as a consequence the effectiveness of such regulation is reduced.

Another challenge is that any statistical analysis relies on historical data. A purely statistical approach is thus limited by the types of shocks and vulnerabilities that we have observed in the available historical data. It is also vulnerable to regime changes in the data. For these reasons, any statistical analysis has to be complemented with thorough theoretical reasoning. Such theoretical reasoning may help identify vulnerabilities that are not apparent from historical data. Moreover, regulators should make use of position data to estimate risk exposures as well as direct and indirect spillover effects. This is important because even a shock that has been observed historically will feed through the system differently in the current environment. The regulator should also complement historical data with stress tests, which can be used to measure the financial system's resilience to a particular stress scenario.

Independently of whether the risk evaluation involves more of a statistical or a stress test approach, one can employ a bottom-up approach or top-down approach. At one extreme, one could collect all individual positions data for all instruments from all 
market participants and conduct a rich bottom-up systemic risk analysis. In contrast, at the opposite end of the spectrum is a top-down approach, which attempts to infer systemic risk by looking at time series of historical prices. The latter approach exploits information aggregation by financial markets, but suffers from the shortcoming of assuming that market prices correctly reflect risks. Sole reliance on this second approach can thus not be sufficient, because risk may be mispriced during the run-up phase - as, for example, during the low-spread environment leading up to the crisis of 2007-09. The challenge with the bottom-up approach, on the other hand, is its informational requirements. The regulator needs to know not only each firm's positions and correlation structure, but also their interaction with the firm's funding structure. Many of these interdependencies are endogenous and depend on institutions' responses to various shocks. Overall, finding the right balance between these two polar approaches is a challenge.

Another issue that arises in estimating systemic risk measures is whether to rely on total assets or equity values to measure risk exposure. In addition, one also has to make a choice as to whether to base the analysis on book values, market values, or both. Using equity prices has the drawback that equity contains an option component whose value increases with risk. An insolvent firm might still have a positive equity value, simply due to the fact that its cash flow is risky and equity holders enjoy limited liability. This is the reason why many studies focus on the market value of total assets, even if they have to be backed out indirectly. Often it is advisable to subtract the face value of the institutions' liabilities. It is important to focus on the face value of liabilities as opposed to the market value, since the market value of a firm's debt decreases as its default probability increases, allowing it to book some artificial increase in profit and market cap.

\subsection{Some Specific Measures of Systemic Risk}

Since the financial crisis of 2007-09, there has been an explosion of suggested systemic risk measures. In a recent survey, Bisias, Flood, Lo, and Valavanis (2012) categorize and contrast more than 30 systemic risk measures. In this chapter, we will discuss only a few of these measures to highlight some main approaches.

Adrian and Brunnermeier (2008) propose the CoVaR measure of systemic risk. The aim of $\mathrm{CoVaR}$ is to measure spillover effects to capture externalities that an individual institution imposes on the financial system, and to outline a method to construct a coun- 
tercyclical, forward-looking systemic risk measure by predicting future systemic risk using current institutional characteristics. The estimation is tractable due to the use of quantile regressions. The prefix "Co, "which stands for conditional, tail correlation, contagion, or comovement, stresses the systemic nature of this measure.

As a measure of systemic risk, CoVaR captures direct and indirect spillover effects and is based on the tail covariation between financial institutions and the financial system. More specifically, the $C o V a R_{q}^{j \mid i}$ denotes the $\operatorname{VaR}$ of the financial system (or of institution $j$ ) conditional on some event $\mathbb{C}\left(X^{i}\right)$ of institution $i$. That is, CoVaR $R_{q}^{j \mid i}$ is implicitly defined by the $q$-quantile of the conditional probability distribution 24

$$
\operatorname{Pr}\left(X^{j} \leq \operatorname{CoVa} R_{q}^{j \mid \mathbb{C}\left(X^{i}\right)} \mid \mathbb{C}\left(X^{i}\right)\right)=q .
$$

We denote institution $i$ 's contribution to $j$ by

$$
\Delta \operatorname{CoVaR} R_{q}^{j \mid i}=\operatorname{CoVaR} R_{q}^{j \mid X^{i}=\operatorname{VaR}_{q}^{i}}-\operatorname{CoVaR} R_{q}^{j \mid X^{i}=\operatorname{Median}^{i}}
$$

The contemporaneous $\Delta C o V a R^{i}$ thus quantifies the spillover effects by measuring how much an institution adds to the overall risk of the financial system.

Depending on the conditioning, one can distinguish between a contribution $\triangle$ Co VaR and the exposure $\triangle$ CoVaR. The contribution $\triangle C o V a R$ answers the question of to what extent conditioning on the distress of institution $i$, e.g., $\mathbb{C}\left(X^{i}\right)=V a R_{q}^{i}$, increases the value at risk of the whole financial system relative to the "normal" state of this institution. The reverse conditioning yields the exposure $\Delta C o V a R$. Conditioning on the whole financial system being at its $V a R$ level answers the question of which institution suffers the most if there is a financial crisis. In other words, the contribution $\triangle C o V a R$ tries to relate to externalities an institution creates to the system, while the exposure $\triangle C o V a R$ relates to how much a bank can fall victim should a crisis erupt. The CoVaR approach is a statistical one, without explicit reference to structural economic models.

The second innovation of Adrian and Brunnermeier (2008) is to relate $\Delta$ Co VaR to macro variables and-importantly - to lagged observable characteristics like size, leverage, and maturity mismatch. The predicted values yield the "forward $\Delta$ CoVaR." This forward measure captures the stylized fact that systemic risk is building up in the

\footnotetext{
${ }^{24}$ Note that Adrian and Brunnermeier (2008) do not follow the usual convention of flipping the sign to make the VaR a positive number. Hence, in the definition below, VaR and CoVaR are negative numbers.
} 
background, especially in low-volatility environments. The "forward $\Delta$ Co VaR" measure avoids the "procyclicality pitfall" by estimating the relationship between current firm characteristics and future spillover effects, as proxied by $\triangle \mathrm{Co} V a R$.

A number of recent papers have extended the CoVaR method and estimated it for a number of financial systems. For example, Adams, Füss, and Gropp (2010) study risk spillovers among financial institutions, using quantile regressions; Wong and Fong (2010) estimate CoVaR for the CDS of Asia-Pacific banks; Gauthier, Lehar, and Souissi (2012) estimate systemic risk exposures for the Canadian banking system. Chan-Lau (2009) controls for some additional common risk factors and calls the resulting measure Co-Risk. Boyson, Stahel, and Stulz (2010) study spillover effects across hedge fund styles in downturns using quantile regressions and a logit model.

In an important early contribution, Engle and Manganelli (2004) develop the CAViaR measure, which uses quantile regressions in combination with a $G A R C H$ model to model the time-varying tail behavior of asset returns. They provide a method to estimate dynamic quantiles. Manganelli, Kim, and White (2011) study a multivariate extension of CAViaR, which lends itself to estimating dynamic versions of CoVaR.

Acharya, Pedersen, Philippon, and Richardson (2010) propose the systemic expected shortfall (SES) measure, which-like the exposure CoVaR - tries to capture the downside risk of a financial institution conditional on the whole system being in financial difficulties. More specifically, $S E S^{i}$ reports the expected amount that an institution is undercapitalized (relative to its capital target $z a^{i}$, a fraction $z$ of its assets $a^{i}$ ) in the event that the financial system is below its aggregate capital target $z A$,

$$
S E S^{i}=-E\left[w_{1}^{i}-z a^{i} \mid W_{1}<z A\right]
$$

The empirical $S E S^{i}$ measure is derived from a linear combination of marginal expected shortfall measures $\left(M E S^{i}\right)$ and leverage. More specifically, Acharya, Pedersen, Philippon, and Richardson (2010) propose to measure the systemic expected shortfall as

$$
S E S_{t}^{i}=0.15 * M E S_{t}^{i}+0.04 * \text { Leverage }_{t} .
$$

This relationship between $S E S, M E S$, and leverage can be justified using a theoretical model that incorporates systemic risk externalities. $M E S^{i}$ is computed as the average return of each firm during the $5 \%$ worst days for the market over the past year. The firm's market leverage is calculated as one plus the ratio of the book value of 
debt to the market value of equity. The reliance of Acharya, Pedersen, Philippon, and Richardson (2010) on contemporaneous daily returns restricts their analysis to crosssectional comparison across banks since applying their method in the time series might lead to procyclicality due to the volatility paradox. Brownlees and Engle (2010) refine the estimation methodology for $M E S^{i}$ and propose a further systemic risk measure called SRISK.

The distress insurance premium (DIP) proposed by Huang, Zhou, and Zhu (2010) is a systemic risk measure that reports a hypothetical insurance premium against catastrophic losses in a portfolio of financial institutions. The systemic importance of an individual institution is defined by its marginal contribution to the aggregate distress insurance premium. Empirically, (risk-neutral) default probabilities are estimated for each institution using credit default swap (CDS) data. Asset return correlations, needed to determine the joint default of several banks, are approximated using estimated equity return correlations. The DIP is then given by the risk-neutral expectation of losses conditional on exceeding a minimum loss threshold.

Segoviano and Goodhart (2009) estimate a multivariate joint distribution of banks' default probabilities employing the non-parametric CIMDO-copula approach, which, unlike correlations, also captures non-linear dependence structures.

Another strand of literature makes use of extreme value theory. The advantage of this theory is that only a few assumptions are needed to characterize the tails of the distribution. More specifically, extreme value theorem states that the maximum of a sample of i.i.d. random variables after proper renormalization converges in distribution to the Gumbel distribution, the Fréchet distribution, or the Weibull distribution. Danielsson and de Vries (2000) argue that extreme value theory works well only for very low quantiles. Hartmann, Straetmans, and de Vries (2004) develop a contagion measure that focuses on extreme events.

More generally, it is useful to draw an analogy between systemic risk measures and the literature on contagion and volatility spillovers (see Claessens and Forbes (2001) for an overview). This literature makes the point that estimates of correlations might be capturing volatility spillovers, as opposed to pure contagion. Forbes and Rigobon (2002) make the argument to disentangle interdependence from contagion.

Finally, some methods build on fully fledged-out structural models. Following the classic Merton model, Lehar (2005) and Bodie, Gray, and Merton (2007) suggest using contingent claims analysis that explicitly takes into account the option component of equity values, derivatives exposures, and potential guarantees. The structural approach 
allows one to derive the value of banks' assets and their interdependence structure across institutions from the observed stock prices and CDS spreads. Such structural approaches have the advantage of explicitly building on a logically consistent model, but have the drawback of requiring the implicit assumption that the model holds with probability one.

\section{Conclusion}

The literatures on bubbles and financial crises have grown tremendously in the past decades. While these literatures have provided us with a number of important insights regarding financial bubbles and crises, a number of important research questions remain. We will use the conclusion to point out a number of open questions that future research might address.

1. How do bubbles start? In most models of bubbles, the bubble cannot start within the model; it has to be present from the time the asset starts trading. Hence, while the existing literature has given us a number of insights for why bubbles may survive, we know much less about their origin.

2. More research is also needed on how bubbles burst. In particular, most theory models of bubbles predict that bubbles burst essentially instantaneously. In practice, however, bubbles often deflate over time. What determines the dynamics of how bubbles burst?

3. The recent crisis has rekindled the debate on whether and how central banks should target bubbles as part of their policy actions. Should they? If yes, how? If not, why?

4. There is an emerging informal consensus that bubbles fueled by credit differ from bubbles that are not fueled by credit. For example, it is sometimes argued that regulators and central banks should lean against credit bubbles, but not against bubbles not fueled by credit. However, more research is needed on this issue, both theoretical (why are credit bubbles more costly from a social perspective?) and empirical (how would one identify credit bubbles?).

5. What macroprudential tools should regulators and central banks deploy? How effective are different macroprudential tools and how do they interact with mon- 
etary policy? This raises the broader question of the interaction between price stability and financial stability and how those goals should be traded off.

6. The corporate finance literature has developed a number of models that capture the sources of financial frictions, but has taken dynamics and calibration less seriously. The macro literature has taken dynamics and calibration seriously, but often is less specific about the source of the underlying frictions. There seems to be large potential in developing a literature that bridges this divide between finance (especially research on financial frictions) and macroeconomic models. For a survey of existing work in macroeconomics, see Brunnermeier, Eisenbach, and Sannikov (2013).

7. The measurement of systemic risk is still in its infancy. To the extent that future regulation should target systemic risk, good measures of such risk are important. An analogy can be made to the development of the national account system after the Great Depression. Part of this question is theoretical: How should we define an operational measure of systemic risk? Part of this question is of an empirical nature: Which data should be collected for financial stability purposes, especially in light of the newly created Office of Financial Research?

8. The policy response to the recent financial crisis has mostly focused on incentive distortions, both as explanations for the crisis and also as the primary point of attack for regulatory interventions. An important open issue is the extent to which behavioral factors drove the crisis, and how regulation should incorporate them. An important challenge in this research agenda is the development of welfare criteria within models with behavioral distortions such that policy recommendations are possible.

\section{References}

Abel, A., N. G. Mankiw, L. H. Summers, and R. J. Zeckhauser (1989): "Assessing Dynamic Efficiency: Theory and Evidence," Review of Economic Studies, $56(1), 1-20$.

Abreu, D., And M. K. Brunnermeier (2003): "Bubbles and Crashes," Econometrica, 71(1), 173-204. 
Acharya, V. V. (2009): "A Theory of Systemic Risk and Design of Prudential Bank Regulation," Journal of Financial Stability, 5(3), 224-255.

Acharya, V. V., D. Gale, and T. Yorulmazer (2011): "Rollover Risk and Market Freezes," Journal of Finance, 66(4), 1177-1209.

Acharya, V. V., L. H. Pedersen, T. Philippon, and M. Richardson (2010): "Measuring Systemic Risk," Working Paper, New York University.

Acharya, V. V., P. Schnabl, and G. Suarez (2012): "Securitization without Risk Transfer," Journal of Financial Economics, (forthcoming).

Acharya, V. V., and S. Viswanathan (2011): "Leverage, Moral Hazard, and Liquidity," Journal of Finance, 66(1), 99-138.

Acharya, V. V., And T. Yorulmazer (2007): "Too Many to Fail-An Analysis of Time-inconsistency in Bank Closure Policies," Journal of Financial Intermediation, $16(1), 1-31$.

- (2008): "Cash-in-the-Market Pricing and Optimal Resolution of Bank Failures," Review of Financial Studies, 21(6), 2705-2742.

Adams, Z., R. Füss, And R. Gropp (2010): "Modeling Spillover Effects Among Financial Institutions: A State-Dependent Sensitivity Value-at-Risk (SDSVaR) Approach," Working Paper, EBS.

Adrian, T., And M. K. Brunnermeier (2008): "CoVaR," Working Paper, Princeton University.

Adrian, T., And H. S. SHIN (2010): "Liquidity and Leverage," Journal of Financial Intermediation, 19(3), $418-437$.

Afonso, G., And H. S. Shin (2011): "Precautionary Demand and Liquidity in Payment Systems," Journal of Money, Credit and Banking, 43, 589-619.

AiYAGARI, S. R. (1994): "Uninsured Idiosyncratic Risk and Aggregate Saving," Quarterly Journal of Economics, 109(3), 659-684.

Allen, F., A. Babus, and E. Carletti (2012): "Asset commonality, debt maturity and systemic risk," Journal of Financial Economics, 104(3), 519-534. 
Allen, F., And D. Gale (1994): "Limited Market Participation and Volatility of Asset Prices," American Economic Review, 84(4), 933-955.

(1998): "Optimal Financial Crises," Journal of Finance, 53(4), 1245-1284.

(2000a): "Bubbles and Crises," The Economic Journal, 110(460), 236-255.

(2000b): "Financial Contagion," Journal of Political Economy, 108(1), 1-33.

(2004): "Financial Intermediaries and Markets," Econometrica, 72(4), 1023-

1061.

(2007): Understanding Financial Crises, Clarendon Lectures in Finance. Oxford University Press.

Allen, F., And G. Gorton (1993): "Churning Bubbles," Review of Economic Studies, 60(4), 813-836.

Allen, F., S. Morris, and A. Postlewaite (1993): "Finite Bubbles with Short Sale Constraints and Asymmetric Information," Journal of Economic Theory, 61(2), 206-229.

Artzner, P., F. Delbaen, J.-M. Eber, and D. Heath (1999): "Coherent Measures of Risk," Mathematical Finance, 9(3), 203-228.

Bagehot, W. (1873): Lombard Street: A description of the money market. H.S. King.

Barth, J. R., A. P. Prabhavivadhana, and G. Yun (2012): "The Eurozone Financial Crisis: Role of Interdependencies between Bank and Sovereign Risk," Journal of Financial Economic Policy, 4(1), 76-97.

Bech, M. L., And K. Soramäki (2001): "Gridlock Resolution in Payments Systems," Danmarks Nationalbank Monetary Review, pp. 67-79.

Bernanke, B. S., And M. Gertler (1989): "Agency Costs, Net Worth, and Business Fluctuations," American Economic Review, 79(1), 14-31.

Bernanke, B. S., M. Gertler, and S. Gilchrist (1999): "The Financial Accelerator in a Quantitative Business Cycle Framework," in Handbook of Macroeconomics, ed. by J. B. Taylor, and M. Woodford. Elsevier. 
Bewley, T. (1980): "The Optimum Quantity of Money," in Models of Monetary Economics, ed. by J. Kareken, and N. Wallace. Federal Reserve Bank of Minneapolis.

Bewley, T. F. (1977): "The Permanent Income Hypothesis: A Theoretical Formulation," Journal of Economic Theory, 16(2), 252-292.

_ (1983): "A Difficulty with the Optimum Quantity of Money," Econometrica, 51(5), 1485-1504.

Bhattacharya, S., and D. Gale (1987): "Preference Shocks, Liquidity, and Central Bank Policy," in New Approaches to Monetary Economics, ed. by W. A. Barnett, and K. J. Singleton, pp. 69-88. Cambridge University Press.

Bisias, D., M. Flood, A. W. Lo, and S. Valavanis (2012): "A Survey of Systemic Risk Analytics," Office of Financial Research Working Paper.

Blanchard, O. J., and M. W. Watson (1982): "Bubbles, Rational Expectations and Financial Markets," in Crises in the Economic and Financial Structure: Bubbles, Bursts, and Shocks, ed. by P. Wachtel. D.C. Heath \& Company.

Bodie, Z., D. Gray, and R. Merton (2007): "New Framework for Measuring and Managing Macrofinancial Risk and Financial Stability," NBER Working Paper.

Bolton, P., And O. Jeanne (2011): "Sovereign Default Risk and Bank Fragility in Financially Integrated Economies," IMF Economic Review, 59, 162-194.

Boyson, N. M., C. W. Stahel, and R. M. Stulz (2010): "Hedge Fund Contagion and Liquidity Shocks," Journal of Finance, 65(6), 1789-1816.

Brownlees, C. T., and R. F. Engle (2010): "Volatility, Correlation and Tails for Systemic Risk Measurement," Working Paper, NYU.

Brunnermeier, M. K. (2001): Asset Pricing Under Asymmetric Information: Bubbles, Crashes, Technical Analysis, and Herding. Oxford University Press.

Brunnermeier, M. K. (2008): "Bubbles," in New Palgrave Dictionary of Economics, ed. by S. N. Durlauf, and L. E. Blume. Palgrave Macmillan.

_ (2009): "Deciphering the Liquidity and Credit Crunch 2007-2008," Journal of Economic Perspectives, 23(1), pp. 77-100. 
Brunnermeier, M. K., And P. Cheridito (2011): "Systemic Risk Management," Working Paper, Princeton University.

Brunnermeier, M. K., A. Crocket, C. Goodhart, A. Persaud, and H. Shin (2009): The Fundamental Principles of Financial Regulation: 11th Geneva Report on the World Economy. CEPR.

Brunnermeier, M. K., T. Eisenbach, and Y. Sannikov (2013): "Macroeconomics with Financial Frictions: A Survey," in Advances in Economics and Econometrics, 10th World Congress of the Econometric Society, ed. by D. Acemoglu, M. Arellano, and E. Dekel. Cambridge University Press.

Brunnermeier, M. K., L. Garicano, P. R. Lane, M. Pagano, R. Reis, T. Santos, D. Thesmar, S. van Nieumerburgh, and D. Vayanos (2011): "European Safe Bonds: ESBies," Euro-nomics.com.

Brunnermeier, M. K., G. Gorton, and A. Krishnamurthy (2012): "Risk Topography," NBER Macroeconomics Annual 2011, 26, 149-176.

(2013): "Liquidity Mismatch," in Risk Topography: Systemic Risk and Macro Modeling, ed. by M. K. Brunnermeier, and A. Krishnamurthy. University of Chicago Press.

Brunnermeier, M. K., And A. Krishnamurthy (eds.) (2013): Risk Topography: Systemic Risk and Macro Modeling. University of Chicago Press.

Brunnermeier, M. K., And J. Morgan (2010): "Clock Games: Theory and Experiments," Games and Economic Behavior, 68(2), 532-550.

Brunnermeier, M. K., And S. Nagel (2004): "Hedge Funds and the Technology Bubble," Journal of Finance, 59(5), 2013-2040.

Brunnermeier, M. K., And M. Oehmke (2012): "The Maturity Rat Race," Journal of Finance, (forthcoming).

Brunnermeier, M. K., And L. H. Pedersen (2005): "Predatory Trading," Journal of Finance, 60(4), 1825-1863.

Brunnermeier, M. K., and L. H. Pedersen (2009): "Market Liquidity and Funding Liquidity," Review of Financial Studies, 22(6), 2201-2238. 
Brunnermeier, M. K., And Y. Sannikov (2010): "A Macroeconomic Model with a Financial Sector," Working Paper, Princeton University.

Brunnermeier, M. K., A. Simsek, And W. Xiong (2012): "A Welfare Criterion for Models with Distorted Beliefs," Working Paper, Princeton University.

Bryant, J. (1980): “A Model of Reserves, Bank Runs, and Deposit Insurance," Journal of Banking and Finance, 4(4), 335-344.

Caballero, R. J., and A. Krishnamurthy (2008): "Collective Risk Management in a Flight to Quality Episode," Journal of Finance, 63(5), 2195-2230.

Calomiris, C. W., and C. M. Kahn (1991): "The Role of Demandable Debt in Structuring Optimal Banking Arrangements," American Economic Review, 81(3), $497-513$.

Carlstrom, C. T., and T. S. Fuerst (1997): "Agency Costs, Net Worth, and Business Fluctuations: A Computable General Equilibrium Analysis," American Economic Review, 87(5), 893-910.

Chan-Lau, J. A. (2009): "Co-risk Measures to Assess Systemic Financial Stability," Working Paper, International Monetary Fund.

Chari, V., and R. Jagannathan (1988): "Banking Panics, Information, and Rational Expectations Equilibrium," Journal of Finance, 43(3), 749-761.

Chen, J., H. Hong, and J. C. Stein (2001): "Forecasting Crashes: Trading Volume, Past Returns and Conditional Skewness in Stock Prices," Journal of Financial Economics, 61, 345-381.

Cifuentes, R., G. Ferrucci, and H. Shin (2005): "Liquidity Risk and Contagion," Journal of the European Economic Association, 3, 556-566.

Claessens, S., And K. Forbes (2001): International Financial Contagion. Springer: New York.

Conlon, J. R. (2004): "Simple Finite Horizon Bubbles Robust to Higher Order Knowledge," Econometrica, 72(3), pp. 927-936.

Copeland, A., A. Martin, and M. Walker (2010): "The Tri-Party Repo Market before the 2010 Reforms," Working Paper, Federal Reserve Bank of New York. 
Cutler, D. M., J. M. Poterba, and L. H. Summers (1989): "What Moves Stock Prices?," Journal of Portfolio Management, 15(3), 4-12.

Dang, T. V., G. Gorton, and B. Holmström (2010): "Ignorance and the Optimality of Debt for Liquidity Provision," Working Paper, Yale University.

Danielsson, J., and C. G. De Vries (2000): "Value-at-Risk and Extreme Returns," Annales d'Economie et de Statistique, 60, 239-270.

Davila, E. (2011): "Dissecting Fire Sales Externalities," Working Paper, Harvard University.

Degryse, H., And G. NGuyen (2007): "Interbank Exposures: An Empirical Examination of Contagion Risk in the Belgian Banking System," International Journal of Central Banking, 3(2), 123-172.

Delong, J. B., A. Shleifer, L. H. Summers, and R. J. Waldmann (1990): "Noise Trader Risk in Financial Markets," Journal of Political Economy, 98(4), 703738.

Demarzo, P. M., R. Kaniel, and I. Kremer (2008): "Relative Wealth Concerns and Financial Bubbles," Review of Financial Studies, 21(1), 19-50.

Diamond, D. W. (1984): "Financial Intermediation and Delegated Monitoring," The Review of Economic Studies, 51(3), 393-414.

- (1997): "Liquidity, Banks, and Markets," Journal of Political Economy, 105(5), 928-956.

Diamond, D. W., and P. H. Dybvig (1983): "Bank Runs, Deposit Insurance, and Liquidity," Journal of Political Economy, 91(3), 401-419.

Diamond, D. W., and R. G. Rajan (2001): "Liquidity Risk, Liquidity Creation, and Financial Fragility: A Theory of Banking," Journal of Political Economy, 109(2), $287-327$.

— (2011): "Fear of Fire Sales, Illiquidity Seeking, and Credit Freezes," Quarterly Journal of Economics, 126(2), 557-591.

Diamond, P. A. (1965): "National Debt in a Neoclassical Growth Model," American Economic Review, 55(5), 1126-1150. 
Diba, B. T., and H. I. Grossman (1988): "The Theory of Rational Bubbles in Stock Prices," Economic Journal, 98(392), 746-754.

Doblas-Madrid, A. (2012): “A Robust Model of Bubbles of Multidimensional Uncertainty," Econometrica, (forthcoming).

Dow, J., And G. Gorton (1994): “Arbitrage Chains," Journal of Finance, 49(3), 819-849.

Duffie, D. (2012): "Systemic Risk Exposures: A 10-by-10-by-10 Approach," in Risk Topography: Systemic Risk and Macro Modeling, ed. by M. K. Brunnermeier, and A. Krishnamurthy. University of Chicago Press.

Duffie, D., And H. Zhu (2011): "Does a Central Clearing Counterparty Reduce Counterparty Risk?," Review of Asset Pricing Studies.

Dufwenberg, M., T. Lindqvist, and E. Moore (2005): "Bubbles and Experience: An Experiment," American Economic Review, 95(5), pp. 1731-1737.

EisenberG, L., And T. H. Noe (2001): "Systemic Risk in Financial Systems," Management Science, 47(3), 236-249.

Engle, R. F., And S. Manganelli (2004): "CAViaR: Conditional Autoregressive Value at Risk by Regression Quantiles," Journal of Business and Economic Statistics, $23(4), 367-381$.

Englund, P. (1999): "The Swedish banking crisis: roots and consequences," Oxford Review of Economic Policy, 15(3), 80-97.

Evans, G. W. (1991): "Pitfalls in Testing for Explosive Bubbles in Asset Prices," American Economic Review, 81(4), 922-930.

FAIR, R. C. (2002): "Events That Shook the Market," Journal of Business, 75(4), 713-731.

Farhi, E., M. Golosov, And A. Tsyvinski (2009): "A Theory of Liquidity and Regulation of Financial Intermediation," Review of Economic Studies, 76(3), 973992.

Farhi, E., And J. Tirole (2012): "Collective Moral Hazard, Maturity Mismatch, and Systemic Bailouts.," American Economic Review, 102(1), 60 - 93. 
Flood, R. P., And P. M. Garber (1980): "Market Fundamentals versus Price-Level Bubbles: The First Tests," Journal of Political Economy, 88(4), 745-770.

Föllmer, H., And A. Schied (2011): Stochastic Financwe. De Gruyter, 3rd edn.

Forbes, K. J., And R. Rigobon (2002): "No Contagion, Only Interdependence: Measuring Stock Market Comovements," Journal of Finance, 57(5), 2223-2261.

Fostel, A., And J. Geanakoplos (2012): "Tranching, CDS and Asset Prices: Bubbles and Crashes," AEJ: Macroeconomics, 4(1), 190-225.

Freixas, X., And B. Parigi (1998): "Contagion and Efficiency in Gross and Net Interbank Payment Systems," Journal of Financial Intermediation, 7(1), 3 - 31.

Friedman, M., And A. J. Schwartz (1963): A Monetary History of the United States 1867-1960. Princeton University Press.

Froot, K. A., and M. Obstfeld (1991): "Intrinsic Bubbles: The Case of Stock Prices," American Economic Review, 81(5), 1189-1214.

Gale, D., and M. Hellwig (1985): "Incentive-Compatible Debt Contracts: The One-Period Problem," Review of Economic Studies, 52(4), 647-663.

Gale, D., And T. Yorulmazer (2011): "Liquidity Hoarding," Working Paper, New York University.

Garber, P. M. (2000): Famous First Bubbles: The Fundamentals of Early Manias. MIT Press, Cambrige, MA.

Garleanu, N., And L. H. Pedersen (2011): "Margin-based Asset Pricing and Deviations from the Law of One Price," Review of Financial Studies, 24(6), 19802022 .

Gauthier, C., A. Lehar, And M. Souissi (2012): "Macroprudential Capital Requirements and Systemic Risk," Journal of Financial Intermediation, 21(4), 594-618.

Geanakoplos, J. (1997): "Promises Promises," in The Economy as an Evolving Complex System II, ed. by W. B. Arthur, S. Durlauf, and D. Lane. Addison-Wesley. 
- (2003): "Liquidity, Defaults, and Crashes," in Advances in Economics and Econometrics: Theory and Applications, Eighth World Congress, Volume 2, Econometric Society Monographs. Cambridge University Press.

- (2010): "The Leverage Cycle," in NBER Macroeconomics Annual 2009, vol. 24, pp. 1-65. University of Chicago Press.

Geanakoplos, J. D., and H. M. Polemarchakis (1986): "Existence, Regularity, and Constrained Suboptimality of Competitive Allocations when the Asset Market is Incomplete," in Uncertainty, Information and Communication: Essays in Honor of Kenneth J. Arrow, ed. by W. P. Heller, R. M. Starr, and D. A. Starrett. Cambridge University Press.

Gennaioli, N., A. Martin, and S. Rossi (2011): "Sovereign Default, Domestic Banks and Financial Institutions," Working paper, CREI.

Gennotte, G., and H. Leland (1990): "Market Liquidity, Hedging, and Crashes," American Economic Review, 80(5), 999-1021.

Goldstein, I., And A. Pauzner (2005): "Demand-Deposit Contracts and the Probability of Bank Runs," Journal of Finance, 60(3), 1293-1327.

Gorton, G. (1985): "Bank Suspension of Convertibility," Journal of Monetary Economics, 15, 177-193.

- (1988): "Banking Panics and Business Cycles," Oxford Economic Papers, 40(4), pp. $751-781$.

— (2010): Slapped by the Invisible Hand. Oxford University Press.

Gorton, G., and A. Metrick (2011): "Securitized banking and the run on repo," Journal of Financial Economics, 104(3), 425-451.

Gorton, G., and G. Pennacchi (1990): "Financial Intermediaries and Liquidity Creation," Journal of Finance, 45(1), 49-71.

Graeber, D. (2011): Debt: The First 5,000 Years. Melville House Publishing.

Gromb, D., and D. Vayanos (2002): "Equilibrium and welfare in markets with financially constrained arbitrageurs," Journal of Financial Economics, 66(2-3), 361 -407 . 
Harris, M., And A. Raviv (1993): "Differences of Opinion Make a Horse Race," Review of Financial Studies, 6(3), 473-506.

Harrison, J. M., And D. Kreps (1978): "Speculative Investor Behavior in a Stock Market with Heterogeneous Expectations," Quarterly Journal of Economics, 89, 323336.

Hart, O., And J. Moore (1994): "A Theory of Debt Based on the Inalienability of Human Capital," Quarterly Journal of Economics, 109(4), 841-879.

HART, O. D. (1975): "On the optimality of equilibrium when the market structure is incomplete," Journal of Economic Theory, 11(3), 418 - 443.

Hartmann, P., S. Straetmans, and C. G. De Vries (2004): "Asset Market Linkages in Crisis Periods," Review of Economics and Statistics, 86(1), 313-326.

Haruvy, E., Y. Lahav, and C. N. Noussair (2007): "Traders' Expectations in Asset Markets: Experimental Evidence," American Economic Review, 97(5), pp. 1901-1920.

Haruvy, E., and C. N. Noussair (2006): "The Effect of Short Selling on Bubbles and Crashes in Experimental Spot Asset Markets," Journal of Finance, 61(3), pp. 1119-1157.

He, Z., I. Khang, and A. Krishnamurthy (2010): "Balance Sheet Adjustment in the 2008 Crisis," IMF Economic Review, 58, 118-156.

He, Z., and A. Krishnamurthy (2012): "A Model of Capital and Crises," Review of Economic Studies, 79(2), 735-777.

Hellwig, M. F. (1994): "Liquidity Provision, banking, and the allocation of interest rate risk," European Economic Review, 38, 1363-1389.

(2000): "Financial Intermediation with Risk Aversion," Review of Economic Studies, 67(4), 719-742.

Holmström, B., And J. Tirole (1997): "Financial Intermediation, Loanable Funds, and the Real Sector," Quarterly Journal of Economics, 112(1), 35-52.

Hong, H., J. Scheinkman, and W. Xiong (2006): "Asset Float and Speculative Bubbles," Journal of Finance, 61(3), 1073-1117. 
Hong, H., And J. C. Stein (2003): "Differences of Opinion, Short-Sales Constraints, and Market Crashes," Review of Financial Studies, 16(2), 487-525.

_ (2007): "Disagreement and the Stock Market," Journal of Economic Perspectives, 21(2), 109-128.

Hoshi, T., And A. K. Kashyap (2004): "Japan's Financial Crisis and Economic Stagnation," The Journal of Economic Perspectives, 18(1), 3-26.

Huang, X., H. Zhou, and H. Zhu (2010): "Measuring Systemic Risk Contributions," BIS Working Paper.

JACKLIN, C. J. (1987): "Demand Deposits, Trading Restrictions and Risk Sharing," in Contractual Arrangements for Intertemporal Trade, ed. by E. C. Prescott, and N. Wallace. University of Minnesota Press, Minneapolis.

JaCklin, C. J., And S. Bhattacharya (1988): "Distinguishing Panics and Information-based Bank Runs: Welfare and Policy Implications," Journal of Political Economy, 96(3), 568-592.

Jensen, M. C., And W. H. Meckling (1976): "Theory of the Firm: Managerial Behavior, Agency Costs and Ownership Structure," Journal of Financial Economics, $3(4), 305-360$.

Jonung, L., L. Kiander, and P. VARtia (eds.) (2009): The Great Financial Crisis in Finland and Sweden: The Nordic Experience of Financial Liberalization. Edward Elgar.

Jorion, P. (2006): Value at Risk. McGraw-Hill, 3rd edn.

Kaminsky, G. L., and C. M. Reinhart (1999): "The Twin Crises: The Causes of Banking and Balance-Of-Payments Problems," American Economic Review, 89(3), $473-500$.

Kindleberger, C. P. (1978): Manias, Panics, and Crashes: A History of Financial Crises. Basic Books.

King, R. R., V. L. Smith, A. W. Williams, and M. V. Van Boening (1993): "The Robustness of Bubbles and Crashes in Experimental Stock Markets," in Nonlinear Dynamics and Evolutionary Economics, ed. by R. H. Day, and P. Chen, pp. 183-200. Oxford University Press. 
Kirchler, M., J. Huber, and T. Stöckl (2011): "Thar She Bursts - Reducing Confusion Reduces Bubbles," Working Paper, University of Insbruck.

Kiyotaki, N., And J. Moore (1997): "Credit Cycles," Journal of Political Economy, 105(2), 211-248.

Kondor, P. (2009): "Risk in Dynamic Arbitrage: The Price Effects of Convergence Trading," Journal of Finance, 64(2), 631-655.

Kreps, D. (1977): "A Note on Fulfilled Expectations Equilibria," Journal of Economic Theory, 14, 32-43.

Krishnamurthy, A., S. Nagel, and D. Orlov (2011): "Sizing Up Repo," Working Paper, Stanford University.

Kupiec, P. (2002): "Stress-testing in a Value at Risk Framework," in Risk Management: Value at Risk and Beyond, ed. by M. Dempster, pp. 76-99. Cambridge University Press.

Kyle, A. S., and W. Xiong (2001): "Contagion as a Wealth Effect," Journal of Finance, 56(4), 1401-1440.

Lamont, O. A., and R. H. Thaler (2003): "Can the Market Add and Subtract? Mispricing in Tech Stock Carveouts," Journal of Political Economy, 111(2), 227-268.

LeHAR, A. (2005): "Measuring systemic risk: A risk management approach," Journal of Banking and Finance, 29(10), 2577-2603.

Lei, V., C. N. Noussair, and C. R. Plott (2001): "Nonspeculative Bubbles in Experimental Asset Markets: Lack of Common Knowledge of Rationality vs. Actual Irrationality," Econometrica, 69(4), 831-859.

Loewenstein, M., and G. A. Willard (2006): "The Limits of Investor Behavior," Journal of Finance, 61(1), 231-258.

Lorenzoni, G. (2008): "Inefficient Credit Booms," Review of Economic Studies, 75(3), 809-833.

Manganelli, S., T.-H. Kim, and H. White (2011): "VAR for VaR: Measuring Systemic Risk Using Multivariate Regression Quantiles," unpublished working paper, $E C B$. 
Martin, A., and J. Ventura (2012): "Economic Growth with Bubbles," American Economic Review, 147(2), 738-758.

Matten, C. (1996): Managing Bank Capital. Wiley.

McKelvey, R. D., and T. R. Palfrey (1992): "An Experimental Study of the Centipede Game," Econometrica, 60(4), 803-836.

Merton, R. C., and A. Perold (1993): "Theory OF RISK CAPital IN FINANCIAL FIRMS," Journal of Applied Corporate Finance, 6(3), 16-32.

Miller, E. M. (1977): "Risk, Uncertainty, and Divergence of Opinion," Journal of Finance, 32(4), 1151-1168.

Miron, J. A., And C. D. Romer (1990): "A New Monthly Index of Industrial Production, 1884-1940," Journal of Economic History, 50(2), pp. 321-337.

Mitchell, M., And T. Pulvino (2012): "Arbitrage crashes and the speed of capital," Journal of Financial Economics, 104(3), 469-490, (forthcoming).

Moinas, S., And S. Pouget (2012): "The Bubble Game: An Experimental Study of Speculation," Working Paper, Toulouse School of Economics.

MorRIS, S. (1996): "Speculative Investor Behavior and Learning," The Quarterly Journal of Economics, 111(4), pp. 1111-1133.

Morris, S., A. Postlewaite, And H. S. Shin (1995): "Depth of Knowledge and the Effect of Higher Order Uncertainty," Economic Theory, 6, 453-467.

Morris, S., And H. Shin (2001): "Rethinking Multiple Equilibria in Macroeconomic Modelling," in NBER Marcoeconomics Annual 2000, ed. by B. S. Bernanke, and K. Rogoff, pp. 139-161. MIT Press.

Neal, L. (1990): The Rise of Financial Capitalism. Cambridge University Press. (2012): "I am Not Master of Events": Speculations of John Law and Lord Londonderry in the Mississippi and South Sea Bubbles. Yale University Press.

Obstfeld, M., And K. S. Rogoff (1996): Foundations of International Macroeconomics. MIT Press. 
Ofek, E., And M. Richardson (2003): "DotCom Mania: The Rise and Fall of Internet Stock Prices," Journal of Finance, 58(3), 1113-1137.

Pastor, L., And P. Veronesi (2006): "Was there a Nasdaq bubble in the late 1990s?," Journal of Financial Economics, 81(1), 61 - 100.

(2009): "Technological Revolutions and Stock Prices," American Economic Review, 99(4), pp. 1451-1483.

Patrik, G. S., S. Bernegger, And M. B. RüEgG (1999): "The use of risk adjusted capital to support business decision making," Casualty Actuarial Society Forum, pp. 243-334.

Porter, D., And V. L. Smith (1995): "Futures contracting and dividend uncertainty in experimental asset markets," Journal of Business, 68, 509-541.

Postlewaite, A., And X. Vives (1987): "Bank Runs as an Equilibrium Phenomenon," Journal of Political Economy, 95(3), 485-491.

Radelet, S., J. D. Sachs, R. N. Cooper, and B. P. Bosworth (1998): "The East Asian Financial Crisis: Diagnosis, Remedies, Prospects," Brookings Papers on Economic Activity, 1998(1), 1-90.

Rampini, A. A., And S. Viswanathan (2011): "Financial Intermediary Capital," Working Paper, Duke University.

Reinhart, C. M., and K. S. Rogoff (2009): This Time is Different: Eight Centuries of Financial Folly. Princeton University Press.

(2011): "From Financial Crash to Debt Crisis," American Economic Review, 101(5), 1676-1706.

Rochet, J.-C., And X. Vives (2004): "Coordination Failures and the Lender of Last Resort: Was Bagehot Right After All?," Journal of the European Economic Association, 2(6), 1116-1147.

Rosenthal, R. (1981): "Games of Perfect Information, Predatory Pricing, and the Chain-Store Paradox," Journal of Economic Theory, 25, 92-100.

Rotemberg, J. J. (2011): "Minimal Settlement Assets in Economies with Interconnected Financial Obligations," Journal of Money, Credit and Banking, 43(1), 81-108. 
Samuelson, P. A. (1958): "An Exact Consumption-Loan Model of Interest with or without the Social Contrivance of Money," Journal of Political Economy, 66(6), $467-482$.

SAto, Y. (2009): "Ranking Concerns of Fund Managers and the Persistence of Bubbles," Working Paper, London School of Economics.

Scheinkman, J., And W. Xiong (2003): "Overconfidence and Speculative Bubbles," Journal of Political Economy, 111(6), 1183-1219.

Schnabel, I., And H. S. Shin (2004): "Liquidity and Contagion: The Crisis of 1763," Journal of the European Economic Association, 2(6), 929-968.

Schularick, M., And A. M. Taylor (2012): "Credit Booms Gone Bust: Monetary Policy, Leverage Cycles, and Financial Crises, 1870-2008," American Economic Review, 102(2), 1029-1061.

Segoviano, M., and C. Goodhart (2009): "Banking Stability Measures," Financial Markets Group Working Paper, London School of Economics and Political Science.

ShilleR, R. J. (2000): Irrational Exuberance. Princeton University Press.

Shleifer, A., And R. W. Vishny (1992): "Liquidation Values and Debt Capacity: A Market Equilibrium Approach," Journal of Finance, 47(4), 1343-1366. (1997): "The Limits of Arbitrage," Journal of Finance, 52(1), 35-55.

Simsek, A. (2011): "Belief Disagreements and Collateral Constraints," Working Paper, Harvard University.

Smith, V. L., G. L. Suchanek, and A. W. Williams (1988): "Bubbles, Crashes, and Endogenous Expectations in Experimental Spot Asset Markets," Econometrica, 56(5), 1119-1151.

Stiglitz, J. E. (1982): "The Inefficiency of the Stock Market Equilibrium," Review of Economic Studies, 49(2), 241-261.

Stiglitz, J. E., AND A. Weiss (1981): "Credit Rationing in Markets with Imperfect Information," American Economic Review, 71(3), 393-410. 
Sturzenegger, F., And J. Zettelmeyer (2006): Debt Defaults and Lessons from a Decade of Crises. MIT Press.

Sunder, S. (1995): "Experimental Asset Markets," in The Handbook of Experimental Economics, ed. by J. H. Kagel, and A. E. Roth, pp. 445-500. Princeton University Press.

Tarashev, N., C. Borio, and K. Tsatsaronis (2009): "The systemic importance of financial institutions," BIS Quarterly Review.

Tasche, D. (1999): "Risk Contributions and Performance Measurement," Working Paper, TU München.

Temin, P., And H.-J. Voth (2004): "Riding the South Sea Bubble," American Economic Review, 94(5), 1654-1668.

Tirole, J. (1982): "On the Possibility of Speculation under Rational Expectations," Econometrica, 50, 1163-1182.

— (1985): "Asset Bubbles and Overlapping Generations," Econometrica, 53(5), $1071-1100$.

Townsend, R. M. (1979): "Optimal Contracts and Competitive Markets with Costly State Verification," Journal of Economic Theory, 21(2), 265-293.

Tsanakas, A. (2009): "To split or not to split: Capital allocation with convex risk measures," Insurance: Mathematics and Economics, 44(2), 268 - 277.

Upper, C., And A. Worms (2004): "Estimating Bilateral Exposures in the German Interbank Market: Is There a Danger of Contagion," European Economic Review, $48,827-849$.

Urban, M., J. Dittrich, C. Klüppelberg, and R. Stolting (2003): "Allocation of Risk Capital to Insurance Portfolios," Blätter der DGVM, 26, 389-406.

Van Boening, M. V., A. W. Williams, and S. LaMaster (1993): "Price Bubbles and Crashes in Experimental Call Markets," Economics Letters, 41(2), 179-85.

Vayanos, D. (2004): "Flight to Quality, Flight to Liquidity and the Pricing of Risk," Working paper, London School of Economics. 
West, K. D. (1987): "A Specification Test for Speculative Bubbles," Quarterly Journal of Economics, 102(3), 553-580.

White, E. N. (2009): "Lessons from the Great American Real Estate Boom and Bust of the 1920s," NBER working paper 15573.

Wong, A., And T. Fong (2010): "An Analysis of the Interconnectivity among the Asia-Pacific Economies," Hong Kong Monetary Authority Working Paper.

Xiong, W. (2001): "Convergence trading with wealth effects: an amplification mechanism in financial markets," Journal of Financial Economics, 62(2), 247-292.

(2012): "Bubbles, Crises, and Heterogeneous Beliefs," in Handbook on Systemic Risk, ed. by J.-P. Fouque, and J. Langsam. Cambridge University Press.

Xiong, W., And J. Yu (2011): "The Chinese Warrants Bubble," American Economic Review, 101(6), 2723-2753.

Zawadowski, A. (2011): "Entangled Financial Systems," Working Paper, Boston University. 